\title{
Gráfica de Atención Completa (G.A.C.), una propuesta metodológica educativa mediante proyectos interdisciplinares para el aprendizaje y mejora de la capacidad de atención-concentración a través del audiovisual y el arte
}

\author{
Por: Lic. Francisco Cuéllar Santiago, Universidad de Granada, España, y \\ Dr. Isidro López- Aparicio Pérez, Universidad de Granada, España \\ Recibido: $\quad 25$ de setiembre, 2017. \\ Aceptado: $\quad 16$ de marzo, 2018
}

\section{RESUMEN}

La presente investigación examina los resultados de la puesta en práctica de una nueva metodología de enseñanza y aprendizaje denominada Gráfica de Atención Completa (G.A.C.), a partir de una investigación comparada (cuantitativa y cualitativa). Los participantes fueron alumnos de I.E.S. en la etapa de secundaria de las CC.AA. de Madrid $(I S I=20)$ y Murcia $(A C L=20)$. La introducción y el marco teórico encuadran la adaptación de la reciente Ley Orgánica sobre Educación (LOMCE) y su falta de atención a la cada vez más demandada alfabetización mediática. Además, se abarca una relación de las metodologías de aprendizaje emergentes desde una visión neurocientífica de la atención y se explican las bases narrativas audiovisuales utilizadas para la creación de esta metodología. Los datos cuantitativos han sido recogidos mediante cuestionarios previos al curso y otro posterior al concluir este, mientras que los datos cualitativos se han obtenido a través de la observación directa y el análisis de los trabajos realizados por los alumnos. Los resultados de la metodología muestran que la mayoría de los participantes ven beneficioso el uso de G.A.C. para la preparación de sus asignaturas, al encontrar un espacio creativo donde expresarse, además de un entorno acogedor de pertenencia con sus compañeros. Asimismo, remarcan que gracias a este método pueden ampliar su tiempo de concentración $30 \%$. Sin embargo, un cierto número de alumnos encuentran dificultad para aplicar la metodología al creer que no tenían habilidades suficientes para llevarla a cabo. La investigación acentúa en sus conclusiones, la necesidad de un trabajo profundo de los gobiernos para fomentar la alfabetización mediática en un contexto social cada vez más dependiente de las tecnologías y la comunicación.

\section{ABSTRACT}

\section{Complete Attention Graphic (G.A.C.), an Educational Methodological Proposal through Interdisciplinary Projects for Learning and Improving Attention-Concentration Capacity through Audiovisual and Art}

This research examines the results obtained in a testing course to analyze a new teaching and learning methodology called GAC (Graphic of Complete Attention), for

1 El profesor Francisco Cuéllar es licenciado en Comunicación Audiovisual, graduado del Centro de Educación Superior Felipe II de Aranjuez, centro adscrito a la Universidad Complutense de Madrid, y doctorando en el departamento de Dibujo e Historia del Arte de la Facultad de Bellas Artes, en la Universidad de Granada, España. Trabaja como profesor de esa misma Universidad, y como Coordinador y Creativo de la Editorial PuntodePapel en Madrid, España. Contacto: fcuellar@correo.ugr.es.

2 El profesor Isidro López-Aparicio es licenciado y doctor en Bellas Artes, graduado en la Universidad de Granada. Trabaja como profesor titular de esa misma casa de estudios. Contacto: isidro@ugr.es.
Francisco Cuéllar Santiago e Isidro LópezAparicio Pérez. Gráfica de Atención Completa (G.A.C.), una propuesta metodológica educativa mediante proyectos interdisciplinares para el aprendizaje y mejora de la capacidad de atención-concentración a través del audiovisual y el arte. Revista Comunicación. Año 39 , volumen 27 , número 1 , enero a junio, 2018. Instituto Tecnológico de Costa Rica. ISSN: 0379-3974 / e-ISSN1659-3820.

\section{PALABRAS CLAVE:}

Educación audiovisual, transversalidad, interdisciplinar, storytelling, videoarte, creatividad, alfabetización mediática.

KEY WORDS:

Media education, transversality, interdisciplinary, storytelling, video art, creativity, media literacy. 
which comparative research (quantitative and qualitative) was used. Participants in the course were secondary students from two schools in the region of Madrid (Secondary School San Isidro=20) and Murcia (High-Performing School in Lorca=20). Both the introduction and the theoretical framework encompass the updated Spanish General Law on Education (LOMCE) and its lack of consideration of the increasingly more necessary media literacy. This study also deals with the relationships between new teaching methodologies from a neuroscientific approach and explains the fundamental audiovisual narratives used for the proposed methodology.

Quantitative data has been gathered from questionnaires before and after the course, while qualitative data has been obtained from direct observation and the analysis of the students' works. The results of the methodology show that most of the participants benefited from the use of GAC when preparing their studies, since they find it a creative platform to express themselves. Results also highlight that this methodology enables students to increase their concentration span in $30 \%$. However, some students find it difficult to apply such methodology because they believe they do not possess the level of skills needed to accomplish it. This research concludes that the Government must make greater efforts in promoting media literacy, especially taking into account contemporary society's great dependency on technology and media.

\section{INTRODUCCIÓN}

La repercusión de la palabra "comunicación" para el año 2018 ha adquirido nuevas connotaciones que difieren sobremanera de las décadas anteriores. No se puede concebir una sociedad sin comunicación. No existiría el conocimiento humano si no se hubiese generado la palabra oral y escrita. Por ello, debe prestársele la suficiente atención para entender hacia dónde se dirige hoy el pensamiento humano y más concretamente, en el mundo de la educación.

En el año 2010 la UNESCO promulgó la Directiva Europea de Servicios Audiovisuales (Gavara de Cara y Pérez Tornero, 2012)), "en donde a través de diversos documentos oficiales, estudios y programas de acción, ha iniciado el camino de proveer indicadores para que la alfabetización mediática e informativa pueda ser evaluada" e insta a cada país a que pongan los medios necesarios para que sea un hecho. El camino recorrido hasta alcanzar este hito es largo y se remonta a la labor pionera que desempeñó la UNESCO entre 1982 (Declaración de Grunwald) y el 2000 (con un punto clave en el Seminario de Sevilla sobre Educación Mediática Seminario UNESCO sobre Educación en Medios-). El proceso tiene su tramo europeo final en la tarea llevada a cabo por la Comisión y el Parlamento entre el 2006 y el 2007, que culmina -precisamente- con la promulgación de la Directiva Europea de Servicios Audiovisuales, codificada en la actualidad en la Directiva 2010/13/UE del Parlamento Europeo y del Consejo del 10 de marzo de 2010, que unifica en un único texto la Directiva 2007/65/CE y la Directiva 89/552/CE.

En este sentido, España promulgó la Ley General de Comunicación Audiovisual para estar dentro del marco jurídico europeo (LGCA - Ley 7/2010 del 31 de marzo), pero desgraciadamente no ha ido más allá de su redacción, ya que no se creó el organismo o entidad correspondiente para el control y desarrollo de las actividades necesarias para una correcta alfabetización mediática. Asimismo y para ahondar más en la problemática, con la nueva Ley Orgánica para la Mejora de la Calidad Educativa (LOMCE) propuesta por el Partido Popular se reducen sobremanera las horas lectivas en términos de conocimiento audiovisual, artístico y musical.

Es aquí donde se situará esta investigación, para construir la explicación de este artículo que intenta demostrar cómo el audiovisual puede generar una nueva metodología de enseñanza-aprendizaje para el docente y discente, siendo una herramienta útil para el proceso de concentración durante el estudio.

Este trabajo intenta cubrir el vacío institucional, siguiendo unas pautas que ya se deben considerar intrínsecas a todo ser humano que haya crecido en lo que McLuhan (1972) definió como "Aldea Global".

\section{MARCO TEÓRICO}

Los medios técnicos cambian, la sociedad también lo hace y como tal, la educación debe reformarse. Así lo marca Acaso (2015) cuando dice "que la educación cambie, se adapte y evolucione 
Gráfica de Atención Completa (G.A.C.), una propuesta metodológica educativa mediante proyectos interdisciplinares para el aprendizaje y mejora de la capacidad de atención-concentración a través del audiovisual y el arte

paralelamente a la sociedad". Por lo que se hace necesaria una revolución educativa, como nombra la propia Acaso. Se trata de abandonar una pedagogía que se ha quedado estancada para caminar a una pedagogía actual y contemporánea. Para ello, Acaso defiende que se deben eliminar las fronteras entre las materias para generar proyectos interdisciplinares, ya que estos favorecen y enriquecen el aprendizaje. Siguiendo esta línea de pensamiento, se cree que la educación debe aproximarse a la afirmación de Robinson (2010), quien piensa que la educación debe equipararse al fluir de la vida, exponiendo que: "la educación se presenta como algo lineal, mientras la vida no lo es; ésta se muestra bajo un patrón orgánico".

Durante los últimos diez años ha crecido enormemente el interés por la alfabetización mediática, sobre todo desde la promulga de la UNESCO en el año 2010. Por eso, diferentes autores expresan que "dada la importancia de medios como la televisión, videojuegos o internet en la educación informal de los niños y jóvenes, sería impensable que la escuela permaneciese ajena a la influencia de los medios" (Gutiérrez, 2012). Así se generan nuevos términos referentes a la sociedad actual como el de "prosumidor" García-Ruiz, Ramírez-García y RodríguezRosell (2014), proponiendo que en la actualidad el "prosumidor" mediático produce y consume información "asumiendo un papel protagonista en el nuevo paradigma de la cultura participativa propiciado por la interactividad tecnológica", recogiendo las palabras de Sandoval y Aguaded (2012).

El 31 de marzo de 2010 salió publicada en el Boletín Oficial del Estado la Ley General de Comunicación Audiovisual en España (LGCA), la cual venía a ser la respuesta del Gobierno español en funciones (PSOE) a la petición del contexto normativo europeo en el ámbito de la alfabetización mediática, que "se ha formulado tradicionalmente como un objetivo de la política educativa y se entiende, en general, como una competencia a adquirir" (Gavara de Cara y Pérez, 2012). No obstante, la LGCA por sí sola no puede llegar a ser ejecutora de las actividades necesarias de control, gestión y proposición que le corresponde, por lo que se haría necesario crear un organismo regulador independiente a tal efecto. Fue en el año 2011 cuando se propuso la creación del Consejo Estatal de Medios Audiovisuales (CEMA). Además, se instó a la creación de organismos reguladores independientes de ámbito autonómico. Es importante entender la necesidad de un organismo como el CEMA, ya que desde algunos años atrás las sociedades han tendido a:

La apropiación de los medios -nuevos y antiguos- por parte de los usuarios: énfasis puesto en la actividad del receptor, en su capacidad de interacción y sus capacidades de apropiarse de los nuevos medios y servicios. Se está pasando de un régimen de difusión centralizada a un régimen de selección personalizada por parte del receptor donde las posibilidades de actuación de éste son constantemente potenciadas (Pérez Tornero, 2008).

Así, queda clara la importancia que conllevaría dentro del ámbito educativo, donde todos los alumnos son prosumidores de contenidos audiovisuales y conviven con toda la información que esto genera.

Ese mismo año, en el 2011, hubo un cambio de Gobierno en España con la entrada al poder del Partido Popular, lo que llevó a una serie de restricciones importantes en cuanto a la alfabetización mediática. La más importante de todas fue el anuncio de que no procedería la puesta en funcionamiento del CEMA y de forma velada, se anunciaría lo que posteriormente se llevó a cabo, atribuir a la Comisión del Mercado de las Telecomunicaciones (CMT) las competencias previstas en la LGCA. Esto significaba que se dejaba en manos del mercado todas aquellas prácticas que deberían ser neutrales, científicas y enfocadas a una alfabetización lo menos sectorizada posible; "pero lo más decisivo, sin duda, es la incidencia de esta suspensión en todo lo que se refiere a la protección de los derechos fundamentales" (Gavara de Cara y Pérez, 2012).

Debe tenerse presente que a nivel educativo, esta LGCA está diseñada para ser ejecutada desde una visión transversal en los planes de estudio. Sin embargo, al no constituirse el ya citado CEMA y darle el control al CMT, la regulación e imposición de los mecanismos vendrá marcado por el gobierno que ostente el poder de turno. Así lo 
ha venido demostrando el Partido Popular con la creación de la LOMCE, en donde se han reducido considerablemente las horas lectivas audiovisuales y su casi total desaparición de los planes de estudios. Gavara de Cara y Pérez (2012) apuntan que la alfabetización mediática, en lo que se refiere a los aspectos prácticos, debería afectar muchos campos: "desde la incorporación de la educación en medios, a la formación inicial y permanente de profesores -además de su inclusión en el currículo educativo básico" - (Gavara de Cara y Pérez, 2012), pero que con las imposiciones del nuevo Gobierno se han visto seriamente dañadas.

Tomando en cuenta este contexto español, vale hacer la siguiente pregunta: ¿qué tipo de población mediática se tiene hoy? Un joven que viva en un país desarrollado con los canales de comunicación habituales recibe de media entre una y cinco horas de consumo audiovisual, ya sea a través de Internet como de la televisión. Estos jóvenes que tengan una edad comprendida entre los 3 y los 17 años para el año 2018 tendrán una concepción completamente distinta de los condicionantes comunicativos que un adulto de 40 años que haya nacido a mediados de los años 70, ya que el propio lenguaje audiovisual ha incidido en su comportamiento y concentración a la hora de procesar la información. El exceso de datos y su velocidad de consumo consigue que la capacidad de atención del niño se haya visto reducido en $50 \%$ en relación con el siglo pasado, en donde se ha pasado de los 20 minutos de atención continuada a los 10 minutos actuales (TokuhamaEspinosa, 2011).

Ante esta bajada tan drástica en la capacidad de concentración, surgieron estudios e investigaciones que permiten al profesor educar de manera más eficiente en el aula, gracias a los avances científicos que la neurociencia está aportando a través de la tecnología de la imagen por resonancia del cerebro. Esta ciencia en gestación denominada Mind, Brain and Education (MBE) y que la Universidad de Harvard apoya con la creación de un máster específico con el mismo título, toma como objetivo elaborar un programa educativo brain-based, como lo describe José Antonio Marina en el prólogo del libro Neurociencia Educativa (Sousa, 2014).
En el 2012, Marina apuntaba que "en el 2002, la OCDE presentó un documento titulado Understanding the brain, en el que se afirmaba que la educación estaba aún en una etapa pre-científica, y que convenía preguntarse si las neurociencias podían ayudar a elevarla a un estatus científico". Por eso, un par de años después se constituyó la "International Mind, Brain, and Education Society" (IMBES), "con el objetivo de la creación de una ciencia transdisciplinar, construida sobre los conocimientos de la neurociencia, la psicología y la educación" (Marina, 2012).

Cinco años después de este cuestionamiento, Tokuhama-Espinosa, en su investigación para la OCDE 2014-2017 sobre neurociencia en educación, presentó una situación importante en cuanto a los cambios en los objetivos educativos generales se refiere, en los que detalló seis puntos fundamentales que han cambiado en la educación del siglo pasado y la época actual:

1. De "pasar clases" a ser un aprendiz a lo largo de la vida.

2. De recursos tradicionales de apoyo (textos) a la integración de la tecnología apropiada.

3. Del mejoramiento de uno mismo a un enfoque de colaboración, cooperación, comunicación, sensibilidad cultural y la construcción de comunidades en el contexto más amplio del grupo.

4. De la igualdad en acceso (todos asisten a la escuela) a la igualdad en calidad.

5. De poca información (pocos tienen acceso) a ser bombardeado por demasiada información (hay que aprender a discernir "buena" de "mala" información).

6. De enseñanza en silos (una materia separada de las otras) a la transdisciplinariedad.

Continúa apuntando que en la educación del siglo XXI se busca conseguir un alumno que sea pensador-crítico-creativo, gente con humildad intelectual, curiosidad y valentía intelectual. Se busca formar personas que sepan usar herramientas para resolver problemas, así como interactuar con grupos heterogéneos, es decir, personas autónomas 
Gráfica de Atención Completa (G.A.C.), una propuesta metodológica educativa mediante proyectos interdisciplinares para el aprendizaje y mejora de la capacidad de atención-concentración a través del audiovisual y el arte

que puedan enfrentar desafíos sin necesidad de que estén encima de ellos apuntando lo que tienen que hacer (Tokuhama-Espinosa, 2017).

Pero como punto base de este nuevo proceso de educación del siglo XXI, Tokuhama-Espinosa (2017) anota la idea fundamental para el docente: "si buscamos formar a personas de este tipo, nosotros (docentes) debemos tener todas esas cualidades". Por ello, lanza las siguientes preguntas a toda la comunidad docente: " $i$ Tenemos nosotros los conocimientos tecnológicos suficientes? ¿Somos capaces de manejar la complejidad? ¿Gozamos los problemas en lugar de buscar simples soluciones? ¿Tenemos un nivel de creatividad suficiente? ¿Somos innovadores? ¿Estamos auto-motivados?" (Tokuhama-Espinosa, 2017).

La concentración hoy es una lucha de poder por la masificación informativa y el bombardeo de datos diario. Es necesario captar la atención de los alumnos y para eso se debe utilizar el mismo código. La transdisciplinariedad e interdisciplinariedad, al igual que se utilizan en otros ámbitos del entretenimiento juvenil como pueden ser los videojuegos, móviles, Internet, audiovisuales, etc., son fundamentales.

No obstante, es importante dar una respuesta a la pregunta que lanzó Tokuhama-Espinosa (2017) y corroboró Marina (2017) "¿Cómo deberíamos dar clases para servir mejor al estudiante que aprende?". En este sentido, Guillén (2017) comenta que "una forma directa de suscitar la atención, un mecanismo imprescindible para el aprendizaje, es despertar la curiosidad, porque aunque a los seres humanos nos cueste reflexionar [...] somos curiosos por naturaleza" y para intentar dar una posible respuesta a esta pregunta y necesidad se ha desarrollado la presente investigación y metodología G.A.C.

\subsection{METOdOLOGÍAS DE ENSEÑANZA}

Antes de adentrarse en las bases de la metodología G.A.C., debe conocerse cuáles son las metodologías educativas que hoy están en boga y que los docentes deberían conocer y desarrollarlas, Ilegando a entremezclarlas para sacar el mayor potencial de cada una de ellas. Estas metodologías están funda- mentadas, como lo muestra Fortea (2009). Por lo tanto, para ajustar y otorgar de rigor a esta investigación se tiene que nombrar aquellas metodologías didácticas que han sido objeto de este estudio para crear la metodología G.A.C. e intentar explicar brevemente en qué consiste cada una. Además, se mencionará un caso particular de enseñanza global de centro: Las Comunidades de Aprendizaje (Flecha y Puigvert, 2002).

Las investigaciones sobre metodologías no pueden probar que unas sean mejores que otras, ya que los factores para considerar eficiente una metodología son muy variables y cada cual -a su modo- es válida para determinadas situaciones. Pero para su perfecta medición hay que tener en cuenta una serie de variables comunes a todas y que Fortea (2009) define como: "1. Resultados de aprendizaje u objetivos previstos; 2. Características del estudiante; 3 . Características del profesor; 4. Características de la materia a enseñar; 5. Condiciones físicas y materiales".

Con tal cantidad de variables sería muy laborioso definir un estándar general común a todas las metodologías, pero sí llegar a comprender que la ideal es aquella que combine varias de ellas. Se entiende desde esta visión que, para conseguir llegar a esta capacidad de unificación de metodologías, el docente debería conocer todas aquellas metodologías más innovadoras y saber utilizarlas. Pero se sabe que esto no ocurre habitualmente.

La web española Reallnfluencers (2017) ofrece una clasificación de metodologías que todo docente del siglo XXI debería conocer para defender sus clases con mayor garantía:

1. Flipped Classroom (Aula invertida): Los materiales educativos primarios son estudiados por los alumnos en casa y luego se trabajan en el aula.

2. Aprendizaje basado en proyectos (ABP): Permite a los alumnos adquirir conocimientos y competencias clave a través de la elaboración de proyectos que dan respuesta a problemas de la vida real. 
3. Aprendizaje cooperativo: Los alumnos trabajan en grupos de entre 3-6 personas, donde cada miembro tienen un rol determinado. Para alcanzar los objetivos es necesario interactuar y trabajar de forma coordinada.

4. Gamificación: La integración de mecánicas y dinámicas propias de juegos y videojuegos en entornos no lúdicos.

5. Aprendizaje basado en problemas: Proceso de aprendizaje cíclico compuesto de muchas etapas diferentes; preguntas que llevan a más preguntas en un ciclo creciente de complejidad.

6. Design Thinking: Consiste en una forma colaborativa de encontrar soluciones innovadoras y creativas a los problemas.

7. Aprendizaje basado en el pensamiento: Enseñarles a contextualizar, analizar, relaciones, argumentar... en definitiva, convertir información en conocimiento.

8. Aprendizaje basado en competencias: Representa un conjunto de estrategias para lograr el desarrollo de habilidades y solidificación de hábitos de trabajo.

9. Estándares de Núcleo Común (Common Core Standars, en inglés): Metodología enfocada para la enseñanza de las matemáticas y como bien explica la publicación digital denominada Revista Educación 3.0 (2016): “[...] Enseñan al alumno a razonar de manera abstracta para entender la forma en la que resuelven los problemas".

10. Método Singapur: Metodología enfocada en la enseñanza de las matemáticas, muy exitosa y con grandes resultados en los informes PISA de los últimos años. Según la publicación digital Educación 3.0 (2016): "Se conforma en base a tres conceptos: concreto, pictórico y abstracto".

Otro método que se cree importante y no aparece en la lista organizada por Realinfluencers es de Flecha García (2002) en donde el propio autor, junto a Puigvert, lo definen como:
[...] un proyecto de transformación de centros educativos dirigido a la superación del fracaso escolar y la eliminación de conflictos. Este proyecto se distingue por una apuesta por el aprendizaje dialógico mediante los grupos interactivos, donde el diálogo igualitario se convierte en un esfuerzo común para lograr la igualdad educativa de todas las alumnas y alumnos (p. 16).

El planteamiento pedagógico de las Comunidades de Aprendizaje utiliza como eje la posibilidad de favorecer el cambio social y disminuir las desigualdades, además de intentar que el contexto social y familiar se introduzca en el aula, transformando y llegando a la utopía educativa de todo el contexto educativo y social.

Todas estas propuestas son válidas en un contexto determinado y por supuesto, para un tipo de discente en concreto. Pero su funcionalidad puede verse mermada en otras situaciones diferentes. Por consiguiente y como ya se ha marcado, la metodología perfecta no existe. No obstante, si se consigue crear una que agrupe las características de una gran mayoría de ellas, es posible estar cerca de una globalizadora. Por lo tanto, con esta investigación se intentará elaborar una que aglutine propuestas de diferentes metodologías, con aspectos que se piensa son necesarios para la etapa de la educación secundaria. Para esto se propone una metodología didáctica que parte de la selección y análisis de un aprendizaje emocional, ayudado por técnicas utilizadas en el sector audiovisual y son de reconocido éxito en el mundo del cine y el marketing, basándose en la estructura del Mito Único de Joseph Campbell (1949).

\subsection{BASES NARRATIVAS AUDIOVISUALES DE LA METODOLOGÍA G.A.C.}

Para crear la metodología G.A.C. se diseña una linealidad de acciones en el transcurso de los 55 minutos de duración de una clase dentro de una asignatura dada, siguiendo un patrón de enseñanza aplicable a cualquier contenido de cualquier materia. En el proceso de creación de esa linealidad de acciones, el docente debe aportar su bagaje personal 
(emocional), donde aplique la impronta necesaria de su visión de los conocimientos que debe impartir.

La necesidad del aprendizaje en inteligencia emocional en cualquier etapa de la educación de un discente viene perfectamente definida por Goleman (1995 y 1996), anotando que esta inteligencia es "un conjunto de capacidades, competencias y habilidades no cognitivas que influyen en la habilidad propia de tener éxito al afrontar las demandas y presiones del medio ambiente y que implican emociones". Las emociones ayudan a crecer, a superar pruebas y además aprender a interactuar con el entorno.

Tanto el discente como el docente deben tener claro este aspecto, ya que como bien recuerda Campillo (2010):

Generalmente, cuando tenemos que recordar a nuestros mejores profesores, es decir, aquellos que más nos aportaron sobre todo beneficios, el 90\% de las cualidades que les solemos atribuir son de carácter socio-emocional: cercanía, confianza, credibilidad, capacidad para motivar, respeto, disponibilidad... Sólo un $10 \%$ de cualidades tienen carácter cognitivo-académico (explicaba muy bien, sabía mucho, era muy culta...).

Son las emociones y la memoria las que protegen en la vida de aquellas situaciones agraviosas que se han vivido, al igual que recuerdan aquellos buenos momentos que se quieren recordar por siempre. Estas emociones deben ir ligadas siempre a la educación, intentar generar sensaciones positivas, para que el aprendizaje así lo sea.

La "narratividad" es el pilar fundamental de esta metodología. Por lo tanto, se han tomado los puntos fundamentales de las estructuras audiovisuales para conformar una línea de tiempo, en la que el discente

Figura 1. La Estructura del Mito Único de Joseph Campbell

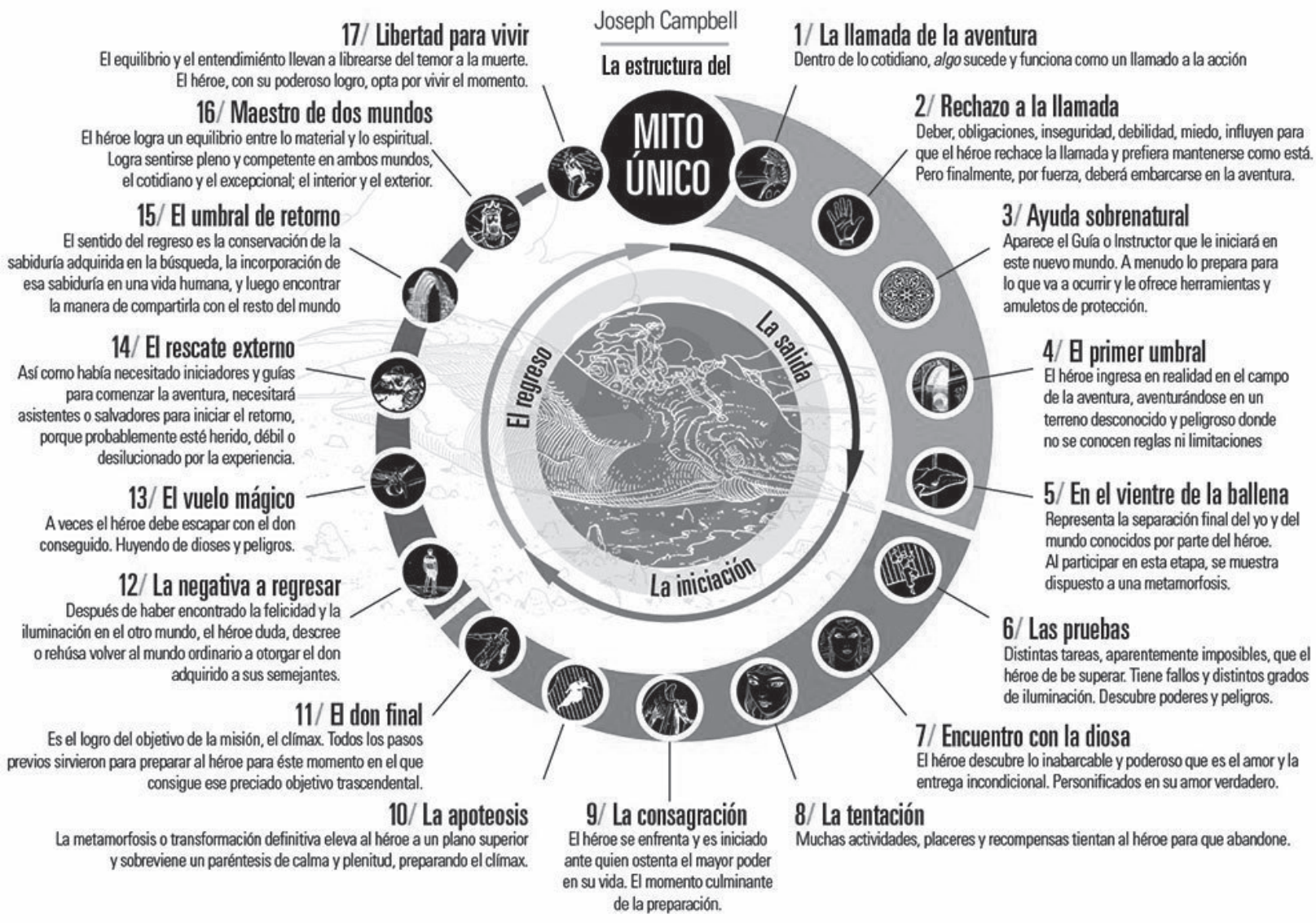

Fuente: Auchterlonie, 2014. 
recibirá los conocimientos que los planes de estudios marcan. El planteamiento metodológico-narrativo parte de la estructura narrativa de Vogler (2002) y Campbell (1949), en donde se exponen los doce estadios del viaje del héroe y que están expresados en la siguiente figura (Auchterlonie, 2014).

Figura 2. Línea temporal del Viaje del Héroe de Christopher Vogler

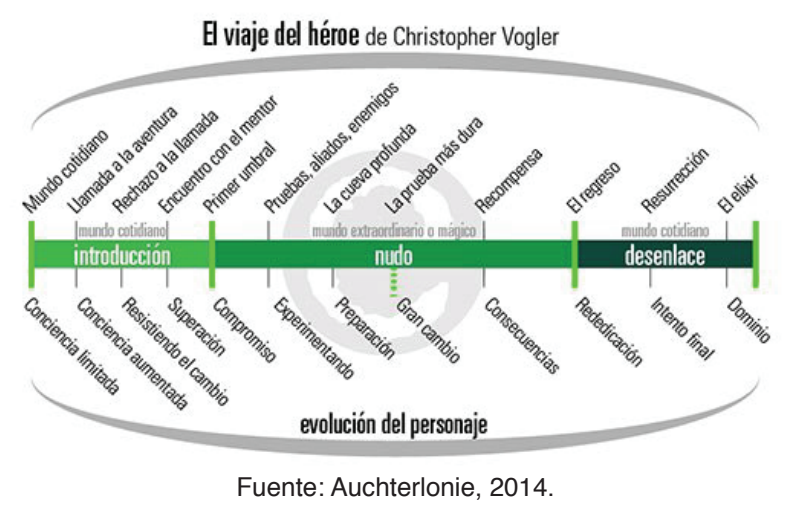

En la gráfica se puede leer la descripción de cada etapa, siguiendo un orden de espacios en los que el lector viaja haciendo valer sus experiencias y emociones. Toda la trama atraviesa tres fases: La Salida, la Iniciación y por último, el Regreso, en donde el protagonista debe hacer valer sus decisiones para atravesar todas y cada una de las etapas.

En relación con el Viaje del Héroe, concepto más actualizado que el de Campbell, es posible atender a su narración con base en el libro de Vogler y que describe la evolución del personaje de forma más sintética, agrupando los estadios en tres grandes fases (Introducción, Nudo y Desenlace), la cual sirve de punto de inicio para la metodología G.A.C. en cuanto a estructura temporal (Auchterlonie, 2014).

Tanto el Viaje del Héroe de Vogler como la Estructura del Mito Único de Campbell tienen una premisa común y es fundamental para la explicación de la investigación: la transformación o cambio del personaje, su evolución. Una historia no será considerada como una gran historia si su protagonista no sufre ese cambio, ese viaje que le convertirá en más sabio, fuerte o amado. La base del éxito es la evolución. Sánchez-Escalonilla (2009) dice al respecto: "[...] la transformación sí se produce en la intimidad del personaje, en su viaje interior, fruto de la nueva visión con que afrontará el mundo primario en lo sucesivo".

Hay que entender que las historias bien narradas alcanzan a un público mayor, atacando directamente las emociones y por lo tanto, permanecerá en el recuerdo del espectador durante más tiempo, consiguiendo que este se adentre en la propia historia.

\section{MATERIALES Y MÉTODOS}

\subsection{PARTICIPANTES}

Para el estudio se toman dos perfiles diferenciados de alumnos de dos comunidades autónomas de España. En los alumnos Tipo 1 se hace una selección multidimensional; es decir, alumnos de diferentes edades convivirán durante el curso. La selección de los alumnos se hace bajo una premisa abierta, dando opción libre a todos aquellos que quieran participar en la investigación, sin distinción por sexo, resultados académicos o motivación. Los alumnos Tipo 1 pertenecían al Instituto de Enseñanza Secundaria San Isidro de Madrid (Curso ISI denominado: Taller de videoarte y experiencia emocional. Curso 2015-2016), (código ISI) y se agrupó a discentes de todos los cursos de la etapa secundaria. Además, se permitió acceder a algunos de $1^{\circ}$ de Bachillerato, con un total de 20 alumnos. El número de alumnos por curso se determinó en: 4 de $1^{\circ} \mathrm{ESO}, 4$ de $2^{\circ}$ $\mathrm{ESO}, 5$ de $3^{\circ} \mathrm{ESO}, 4$ de $4^{\circ} \mathrm{ESO}$ y 3 de $1^{\circ}$ de Bachillerato.

Para el Tipo 2 se decidió contar con discentes de una misma edad, pero con una diferencia más respecto al anterior grupo: trabajar en un contexto de alumnos de Altas Capacidades y así realizar una observación comparativa entre un grupo heterogéneo en cuanto a nivel de comprensión (Tipo 1) y un grupo homogéneo de alto rendimiento. Los alumnos Tipo 2 pertenecían a $3^{\circ}$ de la ESO de Altas Capacidades de Lorca y alrededores, en el Programa de Enriquecimiento Extracurricular de la Región de Murcia (Curso AC denominado: De las emociones al cine - Taller de Videoarte, 2016-2017, código $\mathrm{ACL})$, con un total de 20 alumnos.

La duración del taller fue de seis meses en los dos casos, pero con una cronología diferenciada en 
Gráfica de Atención Completa (G.A.C.), una propuesta metodológica educativa mediante proyectos interdisciplinares para el aprendizaje y mejora de la capacidad de atención-concentración a través del audiovisual y el arte

cada caso: para el de ISI los talleres se realizaron cada semana con sesiones de 2 horas, mientras que para ACL las sesiones fueron de 3 horas cada quince días.

\subsection{DISEÑO}

Con lo explicado en el punto 2.2 surge el planteamiento principal de la investigación: hacer sentir al alumno que él es parte de la historia, parte de los contenidos que debe aprender y que sin su ayuda no podrá resolverse el conflicto: aprobar todas las asignaturas. Para ello se ha diseñado una Gráfica de Atención Completa (G.A.C.), la cual explica la importancia del ritmo y los puntos de giro dentro de una historia narrada.

Para el desarrollo del taller, obviamente se sigue el mismo método que se intenta demostrar. En su diseño se tuvieron en cuenta valores positivos de otras metodologías explicadas en el punto 2.1: escogiendo de Flipped Classroom las ventajas del trabajo audiovisual desde casa; de los $A B P$, realizar microproyectos que aglutinen la materia en diferentes fases; del Aprendizaje Cooperativo la importancia del trabajo en equipo; de la Gamificación, la integración de las estrategias audiovisuales de los videojuegos a la construcción de significación en la narratividad del aula; del Aprendizaje basado en problemas, saber ir resolviendo las preguntas que se van planteando en los estudios; del Design Thinking, la importancia de la innovación en cuanto a la resolución de los conflictos en las dinámicas; del Aprendizaje basado en el pensamiento, la necesidad de enseñar a contextualizar, analizar, relacionar y argumentar, y del Aprendizaje basado en competencias, la adquisición de las habilidades necesarias para superar las competencias que se marcan en los planes.

Como método de estudio y elaboración, se han seguido las bases planteadas y bien conocidas por los docentes del aprendizaje significativo de Ausubel (1963) la cual más tarde sufriría una parcial modificación (Ausubel, Novak y Hanesian, 1978), en donde explica la clave de la teoría del aprendizaje significativo en contraposición con el aprendizaje memorístico con una serie de requerimientos clasificados en:
1. Materiales de aprendizaje significativo.

2. Una disposición por parte de la persona que aprende a enlazar cada concepto del nuevo material con conceptos que ya tiene.

3. Una estructura cognitiva relevante o apropiada en el alumno, es decir, que algunos conceptos de esta puedan ser relacionados, de manera no arbitraria, con los nuevos conceptos. Según González García (1992):

(...) la cumplimentación de estas condiciones, desde un punto de vista didáctico/ metodológico, parece fundamental, pues implica, de una parte, el conocimiento de la estructura cognitiva del alumno, de otra, la planificación adecuada del currículo y la instrucción y, finalmente, el fomento de actitudes favorables a este tipo de aprendizaje, con el potencial de motivación necesario.

Además, el autor marca los mapas conceptuales diseñados por Novak y basados en la teoría del aprendizaje de Ausubel-Novak (Ausubel, Novak y Hanesian, 1978) como la perfecta metodología para implementar el aprendizaje significativo en el aula y señala que:

En la mayor parte de los programas escolares, es frecuente que los alumnos memoricen mecánicamente definiciones o normas de procedimiento sin relacionar los significados de las palabras de las definiciones o de las normas con las ideas que ellos ya comprenden. En realidad, los alumnos llegan a creer que la memorización de la información escolar es la única forma de aprender (p. 54).

Por lo tanto, es muy importante hacer ver a los discentes que otra forma de aprender es posible y que los docentes tienen que mostrarles el camino y para que eso realmente se logre, dice González García (1992), es necesario que los alumnos incrementen su conocimiento en: "1. El proceso de aprendizaje, 2. La naturaleza del conocimiento y 3. Cómo extraer significados de los materiales estudiados". 
Asimismo, afirma González García, (1992): “El mapa conceptual puede ser considerado como una representación visual de la jerarquía y las relaciones entre conceptos contenidas en la mente". Por eso se marca dentro de la metodología G.A.C. con tanta importancia la relación del dibujo con el aprendizaje. Será la creación y comprensión de ideogramas las que ayuden a los discentes a elaborar sus propias herramientas de estudio. Para Stewart, Kirk y Rowell (1979), el mapa conceptual es un instrumento para representar la estructura conceptual de una disciplina o segmento de una disciplina, en dos dimensiones. Por consiguiente, los ideogramas son la mejor manera de crear aprendizaje significativo a través de su propia bidimensionalidad. Un ideograma, según la Real Academia de la Lengua Española (RAE), "es una imagen convencional o símbolo que en la escritura de ciertas lenguas significa una palabra, morfema o frase determinados, sin representar cada una de sus sílabas o fonemas". Estos ideogramas deben ser pensados y dibujados por el alumno a través de la conceptualización de los contenidos a estudiar y su inclusión dentro de la propia historia por narrar.

\subsection{INTERVENCIONES}

En la primera jornada del taller se les entrega a los alumnos unos cuestionarios en los que se analizan los procesos de desarrollo y comprensión respecto a su percepción personal del entorno educativo. Se sigue un proceso de preguntas que evoluciona de lo más general hasta las preguntas más concretas y se busca que el alumno demuestre su capacidad de abstracción por medio del dibujo y la expresión escrita. Por lo tanto, se usan cuestiones abiertas y cerradas dicotómicas, y cuestiones cerradas categorizadas de respuesta sugerida. En el cuestionario diseñado se pueden medir las dimensiones de los conceptos-objetivos de esta investigación (metodología de trabajo, metodología de estudio, estructura mental y por último, sentimiento de pertenencia).

El cuestionario cuenta con 24 ítems, de los cuales, siete son de tipo abierto y 17 de tipo cerrado. Las dimensiones por medir corresponden en un porcentaje de $15 \%$ al tipo de alumno según sus calificaciones, otro $15 \%$ a las creencias respecto a sus capacidades, en $20 \%$ se midieron las dimensiones referentes a la autonomía en relación con las asignaturas, con otro $10 \%$ las metodologías que siguen para estudiar y con $10 \%$ su entorno de aprendizaje; con otro $10 \%$ la capacidad de abstracción conceptual con base en el dibujo y la palabra, y por último, un $20 \%$ midió los sentimientos de inclusión hacia sus compañeros y su centro educativo por medio del sentimiento de orgullo o vergüenza.

En la aplicación de los conocimientos adquiridos por parte del alumno conviene destacar la importancia del arte contemporáneo, el cual sirve de nexo relacional de conceptos a través de las emociones a los elementos cotidianos. Con la muestra de diferentes piezas video-artísticas de importantes creadores audiovisuales (tales como Bill Viola, Chris Marker y Nam June Paik, entre otros), se clasifican previamente a la enseñanza de la metodología G.A.C. una tipología de emociones, que servirán de punto de partida en donde encontrar empatías de trabajo. Se cree que estas empatías emocionales crearán un recuerdo más fiel en el alumno de las piezas audiovisuales mostradas y así tener un recurso al que recurrir a la hora de trabajar sus propios trabajos audiovisuales.

La metodología para el alumno debía ser igual para todos, en la que se diseñaron los siguientes pasos (Tabla 1): 
Gráfica de Atención Completa (G.A.C.), una propuesta metodológica educativa mediante proyectos interdisciplinares para el aprendizaje y mejora de la capacidad de atención-concentración a través del audiovisual y el arte

Tabla 1: Pasos de la metodología

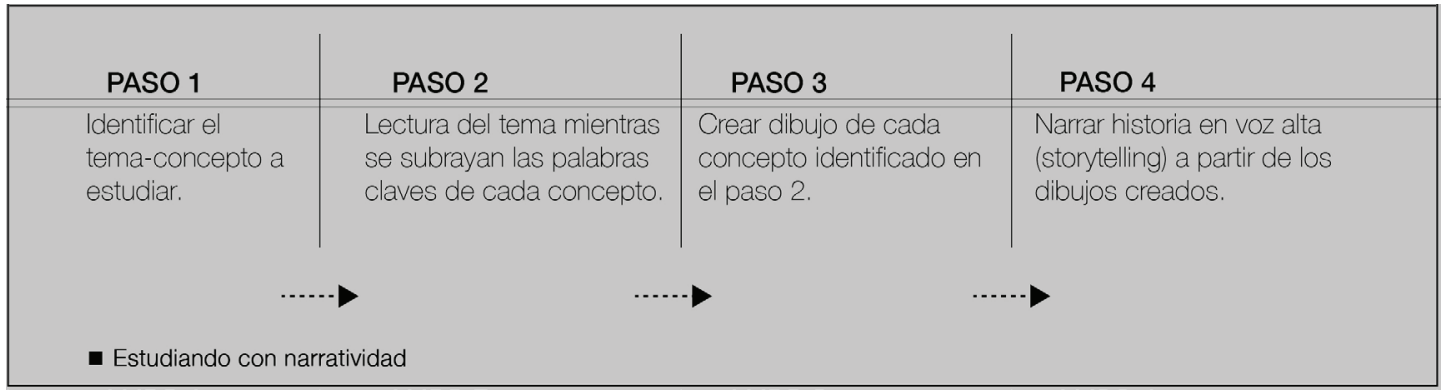

Fuente: elaboración propia

Cada paso de la metodología llevaba implícito un alto grado de diálogo, en el que el docente da margen suficiente al discente para considerar el aula como un espacio de interactuación acogedor.

Se explicó un concepto que hoy es relevante en el mundo audiovisual y empresarial, y del que este trabajo se ha apropiado para las dinámicas: storytelling, el cual Vizcaíno (2016) lo ha definido dentro del marco publicitario como "la instrumentalización de la innata habilidad humana de narrar, a tra- vés del uso de historias con un fin determinado". Se cree firmemente que las historias contadas mediante las emociones con una buena base visual, ayudarán a los alumnos a recibir más eficientemente los contenidos y trabajar de esta manera la inteligencia emocional para crear su propio espacio de pertenencia en el aula.

Para la investigación se siguió el siguiente procedimiento de estudio (Tabla 2):

Tabla 2

División de las jornadas del taller tanto para ISI como ACL

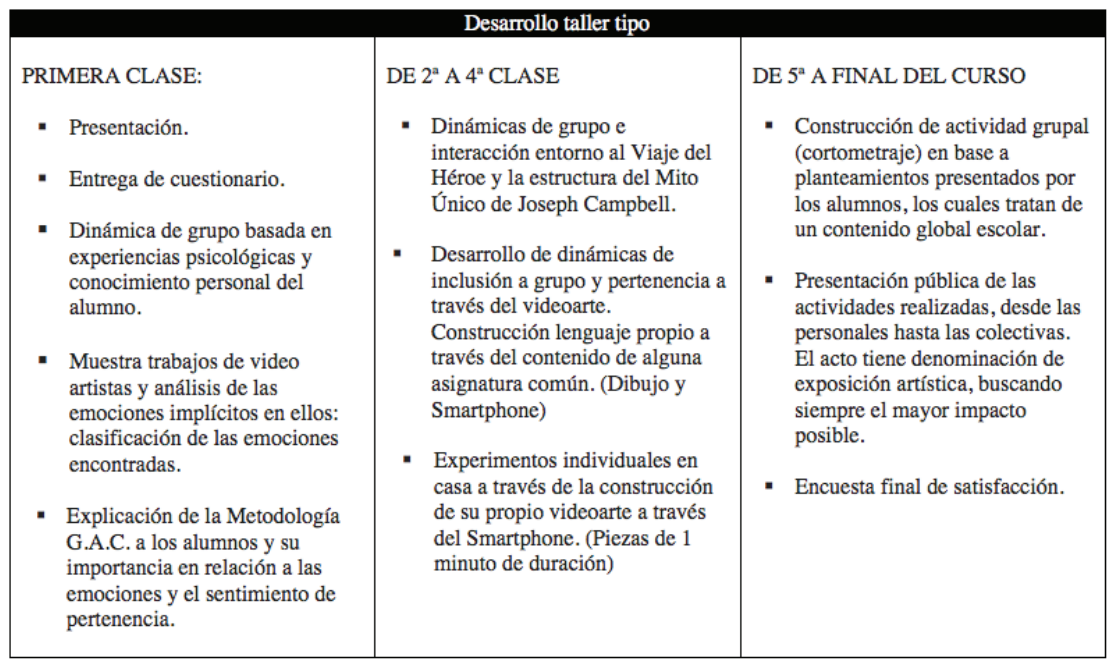

Fuente: elaboración propia

A partir de estos elementos se diseña una nueva gráfica, partiendo de las reglas del Viaje del Héroe de Vogler, donde el alumno será el héroe y tendrá que viajar en cada clase por los contenidos hasta alcan- zar el éxito. Para esto será llevado de la mano del docente, que actuará -como lo denominó Campbell. De esta forma se configura una Gráfica de Atención Completa reflejada en la figura 3. 
Figura 3. La línea de puntos discontinua refleja la curva de atención de la audiencia en una charla de 45 minutos sin elementos de bidireccionalidad.

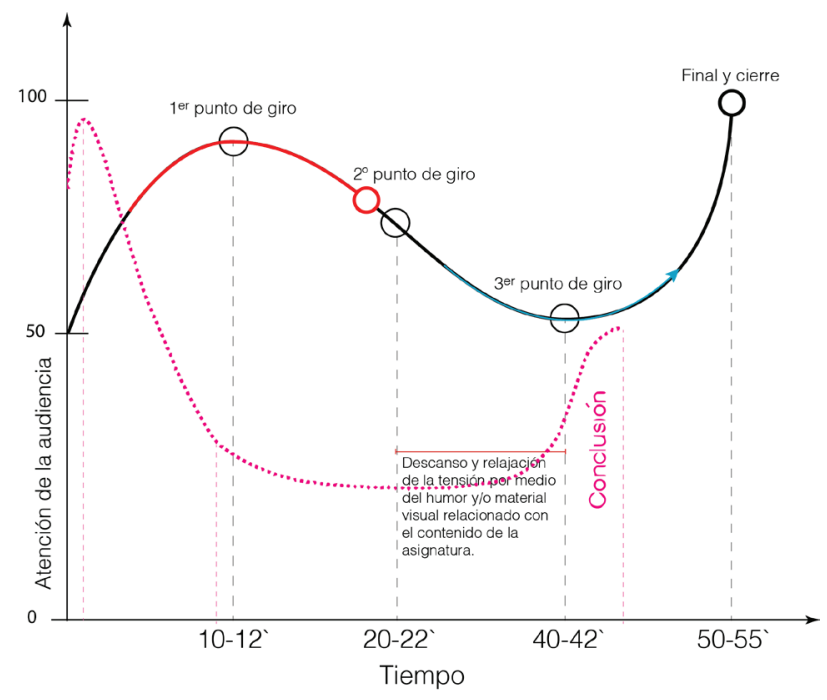

Fuente: Muñoz (2010)

Se define el concepto de Plot Point para que el alumno entienda la importancia de los giros. Debido a esto, se hace uso de la matización de Kristin Thompson (1999): “Un plot point es un evento o acontecimiento que engancha la historia y la hace girar en otra dirección" y añade en su libro que se decanta por el término turning point -punto de inflexión-, "ya que implica un evento crucial o cambio, mientras que un plot point simplemente parece implicar un evento significativo que podría o no crear una transición mayor". Entonces, estos incidentes o eventos son los que hay que definir previamente en relación con el contenido global a impartir, que serán tomados como lugares donde mostrar elementos audiovisuales, gráficos o performativos. El alumno viajará por todos los estadios marcados en la explicación, llevado por el ritmo de la historia por contar.

La historia comienza en un punto determinado donde a los discentes se les considerará neutrales, partiendo de una información base que servirá de anclaje. Poco a poco hay que subir la intensidad y el ritmo hasta alcanzar el primer punto de giro, el cual debe ser un concepto importante de la enseñanza de esa sesión. Este punto de giro deberá venir cargado de dinámicas para el alumno, ya sea por medio de recursos gráficos o actividades. Seguidamente se descenderá la intensidad, creando un ambiente de trabajo óptimo para la asimilación del contenido. A mitad de la G.A.C. se comprueba que hay un descenso en la concentración. Esto es muy importante para volver a captar la atención, ya que -utilizando las premisas del Viaje del Héroeel protagonista tiene que cruzar la Cueva profunda, adentrándose en la prueba más dura que le debilitará sobremanera, pero obtendrá una Recompensa, para posteriormente llegar al Regreso. Es en este punto donde con gran impulso debe llegar hasta el final de la historia (clase). En la gráfica se añade el estudio de Muñoz (2010), donde muestra la gráfica de atención para una conferencia de 45 minutos sin bidireccionalidad; así el lector podrá comprar las diferencias de ritmos e intensidades.

El siguiente paso para comprender la metodología de G.A.C. fue la asimilación de la narratividad. La actividad consiste en definir un contenido específico de alguna asignatura en la que el discente tenga dificultad para aprender y aprobar. Una vez definido el contenido a investigar, el alumno debe disponer los planteamientos necesarios para crear su propio storytelling. El dibujo (ideograma) debe ser el pilar fundamental a la hora de construir su narrativa.

Para explicar la importancia del dibujo, Ainsworth y Russell (2011) han señalado que "realizar visualizaciones es esencial para el pensamiento científiCo" y además que "los investigadores no sólo usan palabras sino que también se apoyan en diagramas, gráficos, vídeos, fotografías y otras imágenes para hacer descubrimientos". Es por esto que no se debe olvidar que tener destreza a la hora de conceptualizar ideas y pensamientos en dibujos más o menos abstractos es fundamental para el buen desarrollo del intelecto.

Una vez que el discente tiene centrados los conceptos, debe proceder a realizar la síntesis del storytelling, siendo capaz de narrar su propio viaje del héroe en los términos de la asignatura de estudio. En la figura 4 se ve un ejemplo de storytelling realizado por el alumno ISI16, en relación con la asignatura de francés: 
Figura 4. Imagen tomada de la exposición en clase del alumno ISI16 de su storytelling

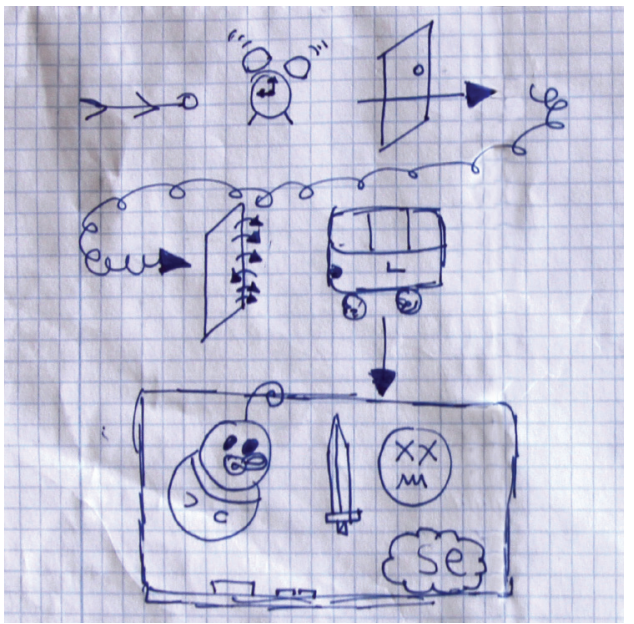

En su exposición en el aula, marcó los pasos de todo el temario que debía preparar para un próximo examen y señaló que la síntesis de los conceptos en ideogramas le sirvió para recordar todos los puntos por desarrollar el día de la prueba. Explicación transcrita de ISI16:

El primer "dibujo" es un hombre/mujer tumbad@. Haciendo una referencia a "tomber". (Porque está tumbado). La segunda es "rester" (porque cuando suena una alarma quieres quedarte, rester, un poco más). La tercera es "passer" (pasar por la puerta). La cuarta es "retourner" (ir hacia el salón). La quinta son varios verbos que son de ir $y$ venir: aller, entrer, venir, arriver, sortir. (haciendo que vas adentro y afuera porque se olvidan cosas y hay que volver) La sexta es un autobús "monter" (porque voy en autobús todos los días al instituto) La séptima es "descendre". (porque desciendes del bus y llegas al instituto). La octava es una pizarra porque damos historia ese día y nos enseñan la vida de una persona: nace "naître", le hacen caballero "devenir" y por último muere: mourir". Son de la familia "se" (para hacer "se revellier" por ejemplo).

El siguiente paso en la investigación es la creación de microvideos (videoartes) por parte de los alumnos de no más de 1 minuto, donde plasman las emociones que sienten en relación con las asignaturas que cursan. Además, los contenidos deben interactuar con la materia que han seleccionado/estudiado para la metodología. Tras poner en común todas las emociones y explicar brevemente los motivos de su elección, se hace una comparativa con los trabajos de videoartistas mostrados en clases anteriores, analizando los métodos de enseñanza de las emociones aplicados por ellos y los propios artistas. De esta forma, se afianzan los conceptos narrativos de expresión emocional, intentando alcanzar de esta manera un discurso propio.

Se continúa con el trabajo grupal, donde se desarroIla en concepto de temática libre un cortometraje común, de entre 5 y 15 minutos, y que debe seguir los pasos marcados anteriormente con el Viaje del Héroe de Vogler. Así, se construye una trama cerrada en el que se ejemplifica un personaje y su evolución, hasta conseguir construir una historia completa. Una vez diseñado y escrito el guion literario y técnico desarrollado por los alumnos, se pasa al rodaje de este, el cual se divide en 3 o 5 sesiones.

Para la exposición final, los alumnos serán parte del equipo técnico y artístico del evento, donde se permitirá el acceso a familiares y alumnos para visionar los trabajos realizados.

Figuras 5, 6 y 7. Exposición final taller ACL el día de la presentación. La figura 5 pertenece a momentos previos al inicio, la figura 6 a la entrada de padres al evento, mientras que la figura 7 pertenece a la presentación de un videoarte.
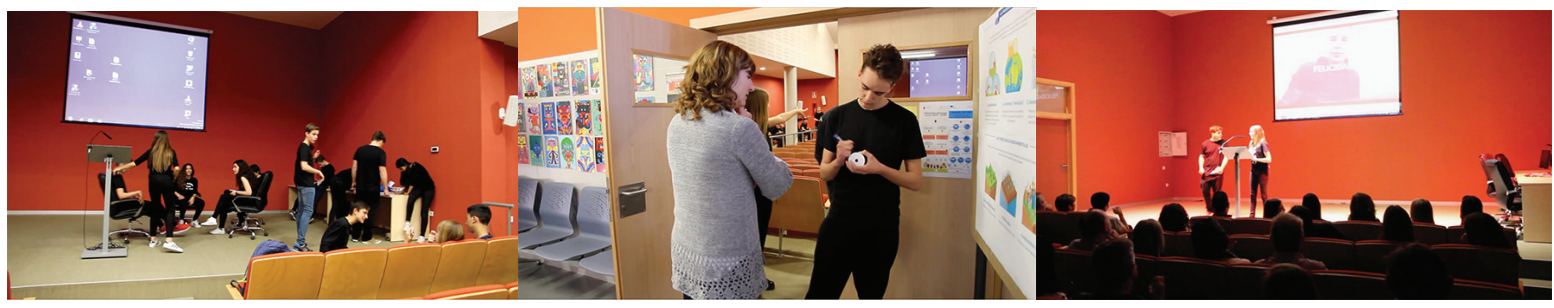

Fuente: elaboración propia 


\subsection{ANÁLISIS}

Para el estudio de la investigación se ha seguido el procedimiento de la Teoría Fundamentada, concretamente un análisis comparativo utilizando el método de Glaser y Strauss (Andréu y Pérez, 2007) el cual permite descubrir aquellos aspectos que son relevantes de una determinada área de estudio (Strauss y Corbin, 1990). Con este modelo, se busca una mejor comprensión de los datos obtenidos de la observación de los talleres, los datos recabados mediante las piezas audiovisuales realizadas por los alumnos y las respuestas vertidas por estos en los cuestionarios con preguntas abiertas y cerradas que se plantearon, tanto al inicio como al final del taller.

Con los datos obtenidos de los cuestionarios iniciales $(\mathrm{Cl})$ rellenados por los alumnos del ISI y $\mathrm{ACL}$, fue posible realizar el análisis para su clasificación, de la cual se dará cuenta en el apartado de resultados.
Ahora, el estudio se centrará en explicar el análisis cualitativo que se ha elaborado con la Guía de Observación (GdO), Ilevada a cabo a lo largo de los seis meses de taller, tanto del ISI como de ACL. La GdO evalúa al alumno desde tres ángulos diferenciados: a) exposición en el encerado del aula de su metodología G.A.C. desarrollada a través del contenido de la materia elegida, b) la participación en clase a lo largo del taller y la realización de las dinámicas planteadas por el docente y c) exposición y explicación del videoarte realizado. Los datos fueron recogidos gracias a la observación directa, utilizando unos ítems preestablecidos en una tabla, creada a partir de la Guía de Observación para la Detección de Necesidades Educativas propuesta por el Consejo Nacional de Fomento Educativo de México (Pública, 2010) y que fue adaptada para los discentes españoles. Dicha guía adaptada constaba de las siguientes dimensiones:

Tabla 3

Dimensiones GdO G.A.C.

TESIS DOCTORAL FRANCISCO CUÉLLAR SANTIAGO

METODOLOGIA G.A.C. LA EDUCACIÓN AUDIOVISUAL. UNA INVESTIGACIÓN DE INTERACCIÓN INTERDISCIPLINAR EN LAS ARTES AUDIOVISUALES Y SU RELACIÓN EN EL ENTORNO EDUCATIVO.

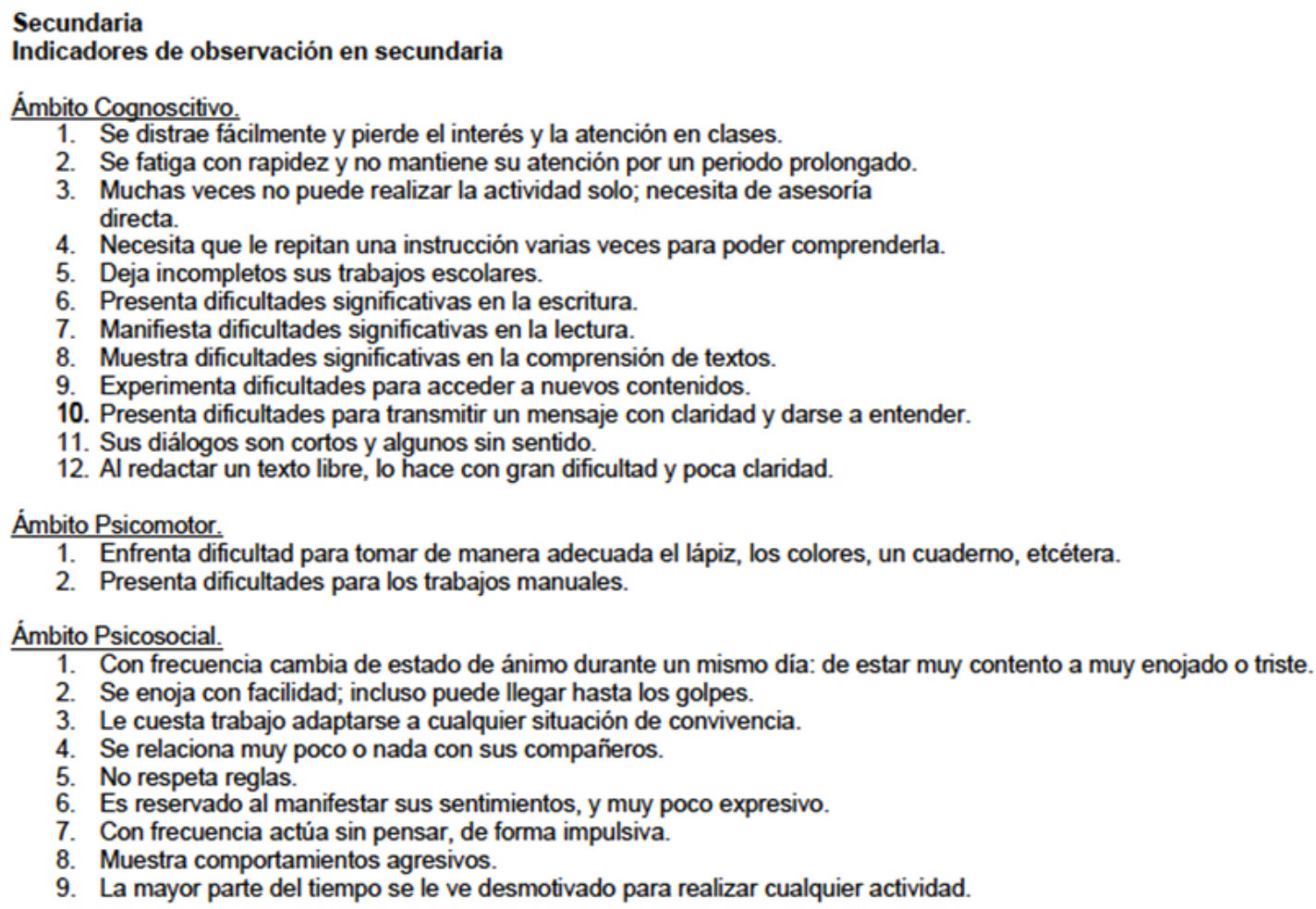

Fuente: elaboración propia 
La selección de las dimensiones preparadas para la investigación de este artículo han seguido un proceso de criba con respecto a los propuestos por el CONAFE.

Los datos recogidos mediante la observación se analizaron en dos fases: una primera para los contenidos teóricos, dinámicas y exposición de cada alumno, y una segunda recogida de datos durante el proceso de grabación del cortometraje y los videoartes. Para recabar los datos, se usó el método híbrido propuesto por Álvarez y Jurgüenson (Álvarez, 2003), en el que se utilizaron algunas herramientas de tipo cuantitativo dentro de una investigación cualitativa.

Los indicadores cognoscitivos están centrados en todos aquellos aspectos referentes a la concentración, atención y capacidad del alumno para el estudio. Por su parte, los indicadores psicomotores se centran en los aspectos físicos del discente y sus capacidades motoras y de destrezas. Por último, los indicadores psicosociales miden los aspectos relacionales del alumno con su entorno educativo, ya sean docentes o compañeros. Cada apartado cuenta con distintos indicadores de observación del alumno, que fueron evaluados individualmente día a día en dos fases diferenciadas, una inicial (primeras dos semanas de taller) y otra final (última semana de taller) donde poder realizar de esta manera una comparativa de evolución. Para concluir el análisis, se les solicitó a los alumnos que rellenasen unos cuestionarios finales de satisfacción (CF).

\section{RESULTADOS}

De la primera fase de investigación se obtuvo de los $\mathrm{Cl}$ una clasificación de los alumnos dividida en cuatro estadios, los cuales sirvieron para mostrar especial atención en aquellos que denotaban mayor dificultad para adquirir los conocimientos necesarios (Tabla 4).

Tabla 4: Tipología de alumnos obtenidos de los cuestionarios iniciales

\begin{tabular}{|c|c|c|c|}
\hline $\begin{array}{l}\text { Tipo1. Alumnos } \\
\text { altamente autónomos y } \\
\text { con gran capacidad de } \\
\text { abstracción simbólica, } \\
\text { con alto sentimiento de } \\
\text { pertenencia al centro } \\
\text { escolar y hacia sus } \\
\text { compañeros. }\end{array}$ & $\begin{array}{l}\text { Tipo 2. Alumnos con } \\
\text { necesidades de atención } \\
\text { pero lo suficientemente } \\
\text { autónomos como para } \\
\text { sacar provecho de los } \\
\text { estudios. Nivel } \\
\text { intermedio de } \\
\text { abstracción simbólica } \\
\text { pero con alta capacidad } \\
\text { psicomotriz (destreza). } \\
\text { Poseen un amplio } \\
\text { sentimiento de } \\
\text { pertenencia hacia sus } \\
\text { compañeros pero no tan } \\
\text { alto hacia el centro } \\
\text { escolar. }\end{array}$ & $\begin{array}{l}\text { Tipo 3. Alumnos con } \\
\text { necesidades de atención } \\
\text { y concentración pero alta } \\
\text { capacidad para los } \\
\text { trabajos de destreza } \\
\text { manual. Nivel bajo de } \\
\text { abstracción simbólica. } \\
\text { Bajo sentimiento de } \\
\text { pertenencia en cualquier } \\
\text { ámbito. }\end{array}$ & $\begin{array}{l}\text { Tipo 4. Alumnos con } \\
\text { bajas capacidades de } \\
\text { atención y concentración } \\
\text { y bajas capacidades en } \\
\text { destreza. El sentimiento } \\
\text { de pertenencia al centro } \\
\text { y a los compañeros } \\
\text { apenas existe. }\end{array}$ \\
\hline
\end{tabular}

Fuente: elaboración propia

Esta tipología es global y generalizadora para los dos grupos de discentes observados. Pero debe anotarse que en el grupo ACL, el porcentaje de alumnos Tipo 1 fueron los predominantes; en $80 \%$ y en $20 \%$ los Tipo 2, mientras que los Tipos 3 y 4 no obtuvieron ningún resultado. En el grupo ISI -por su parteel porcentaje estuvo más repartido entre el resto de tipologías, siendo la predominante los Tipos 2 y 3, dejando en minoría a los Tipos 1 y 4 (véase figura 8). 
Figura 8. Tipologías de los alumnos investigados y su porcentaje

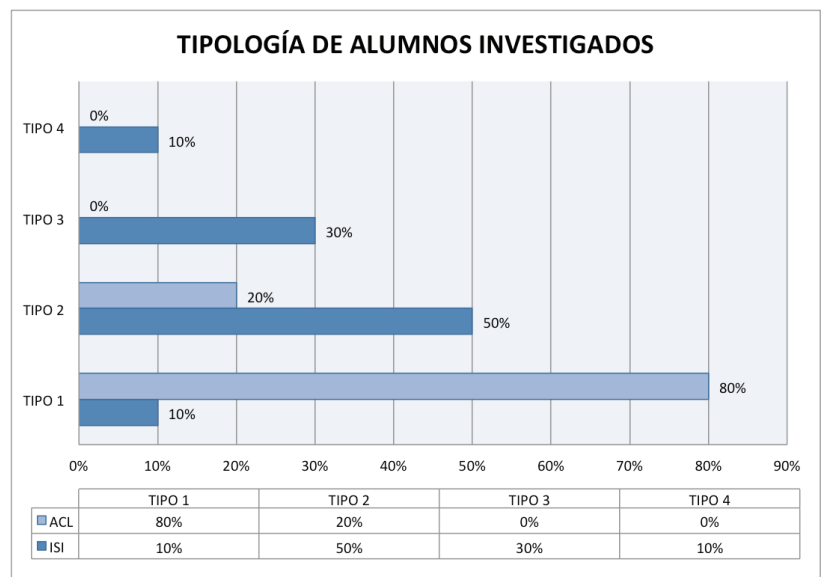

Fuente: elaboración propia

Una vez clasificados los alumnos por su tipología, se deben ofrecer los resultados de las tipologías de emociones que fueron clasificadas por estos en las primeras sesiones tras el visionado de los videoartes. Estas emociones son las que los discentes posteriormente trabajaron en sus propias piezas audiovisuales. De la observación y exposición de los alumnos se consiguió la siguiente clasificación de emociones y el porcentaje de uso en sus trabajos audiovisuales (figuras 9 y 10):

Figura 9. Emociones trabajadas por ACL Lorca

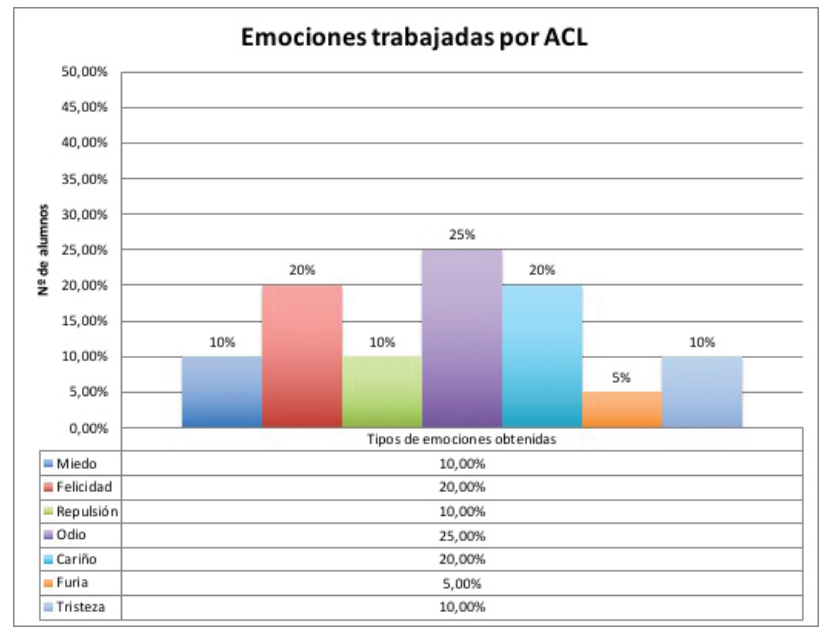

Fuente: elaboración propia
Figura 10. Emociones trabajadas por ISI Madrid

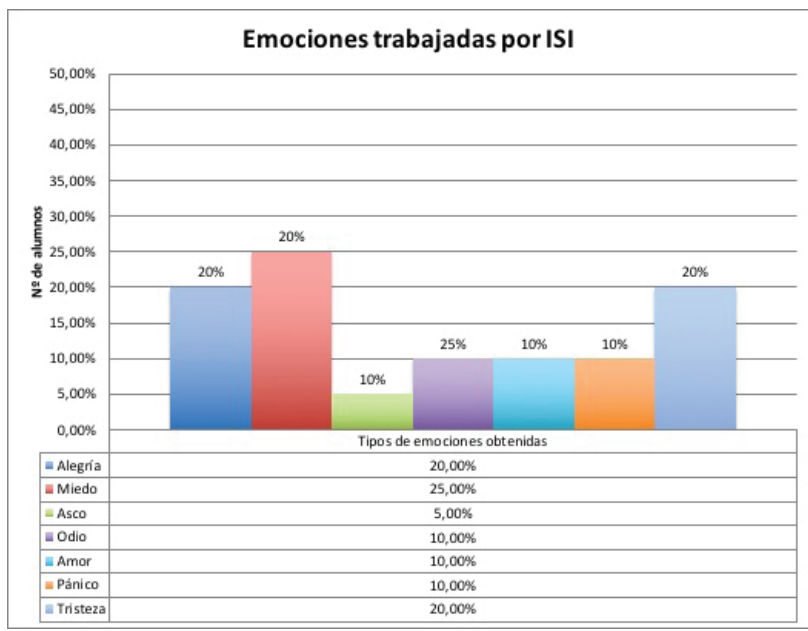

Los resultados de las emociones expuestas por los alumnos fueron comparadas con las que Goleman (1996) clasificó y que sirvió para que los discentes entendieran la importancia de las emociones en el entorno diario, tanto laboral como personal. La clasificación que Goleman propuso se resumía en dos grandes apartados donde incluirlas. Por un lado, estarían las emociones básicas o primarias, que vienen marcadas por una expresión facial. Existe cierta polémica para llegar a un entendimiento en su clasificación, pero normalmente se suele usar la de alegría, tristeza, miedo, asco e ira. Por otro lado, se tendrían las emociones secundarias o complejas, ya que surgen de las primarias y no presentan expresiones faciales, como pueden ser satisfacción, pena, terror, repulsión o furia, respectivamente.

Como ya se ha explicado en el apartado 3.3 de esta investigación, el $\mathrm{Cl}$ diseñado tenía cuatro fases de análisis (método de trabajo, estudio, estructura mental y sentimiento de pertenencia) y era importante investigar el nivel de abstracción de los alumnos en cuanto a su relación con los ideogramas que deberían desarrollar posteriormente dentro de G.A.C. Así que -tras analizar los $\mathrm{Cl}$ - se observó que aquellos alumnos con alta capacidad en el ámbito de estructura mental, al preguntárseles "¿Por norma general sueles memorizar conceptos en base a imágenes o en base a palabras?" mostraron en $75 \%$ una capacidad de abstracción simbólica de la imagen muy baja, siendo mayor en los aspectos de palabra. En cambio, los alumnos de ISI obtuvieron un 65\% 
de mayor grado de relación con la imagen que con la palabra, el cual obtuvo 35\% del total, como se puede observar en las figuras 11 y 12 .

En relación directa con la cuestión planteada de palabra e imagen, se les solicitaba a los alumnos un pequeño ejercicio de interpretación de una imagen dada, a modo de pregunta abierta de la que se podría obtener un dato más fiable de la cuestión anterior (figura 13).

Figuras 11 y 12. Respuestas Cl19, tanto de ISI como de ACL
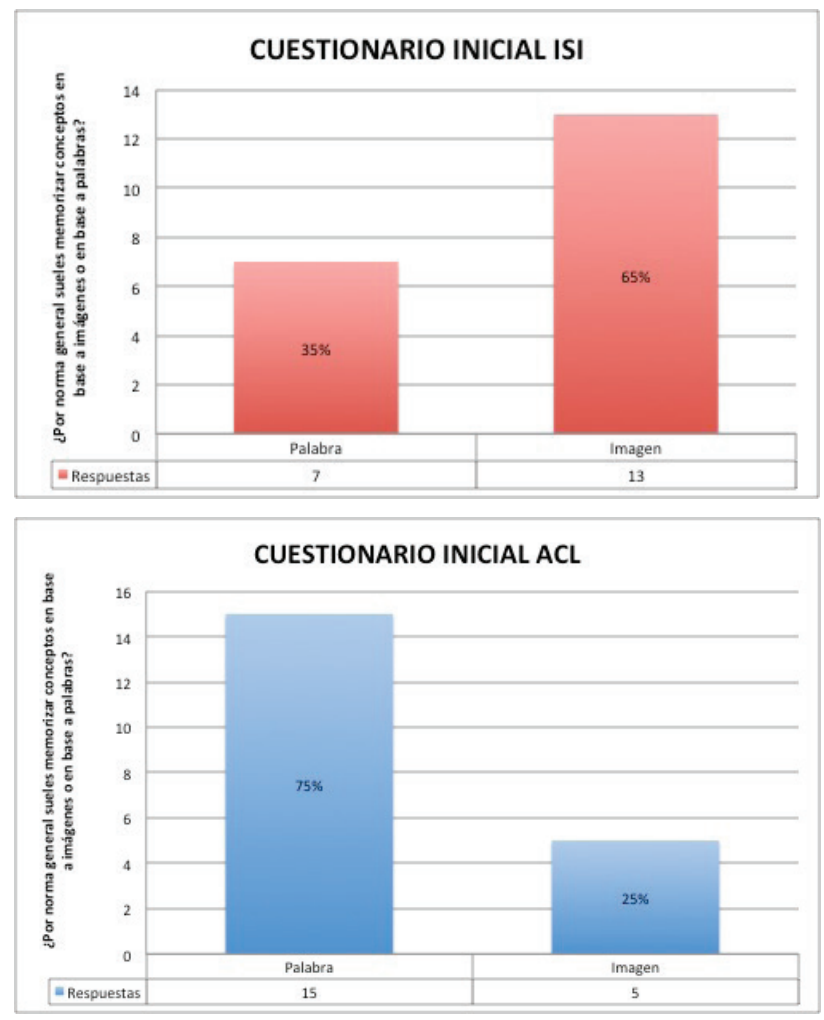

Fuente: elaboración propia

Figura 13. Respuesta alumno ISI14 en relación con la pregunta CI20 del cuestionario. Fotografía tomada del cuestionario original

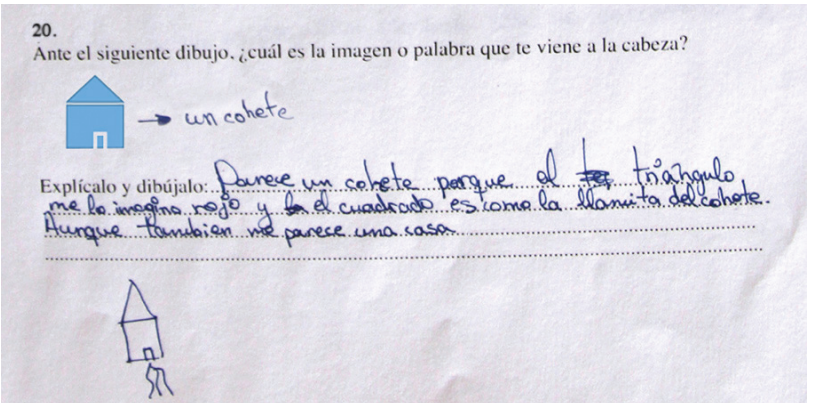

Los resultados de la primera fase de GdO denotaron unos datos esclarecedores con respecto a las carencias de concentración y atención de los alumnos de ISI en contraposición con los de ACL, situación que se invierte cuando se habla de los datos de cuestiones psicomotrices y psicosociales. En relación con las dimensiones cognoscitivas de inicio y final del taller se observa que las capacidades de atención y fatiga se ven reducidas en $30 \%$ en los dos casos de estudio, gracias al uso de G.A.C., al igual ocurre con los valores de fatiga y comprensión, en donde los márgenes de mejoría se han visto superados en $20 \%$ en los dos casos.

Los alumnos de ACL denotaron gran mejoría en la medición 5 de la GdO Cognoscitiva, al tener un porcentaje de mejoría del $15 \%$ respecto a la medición inicial. Vale anotar que en las mediciones realizadas en ISI respecto a los apartados 6 y 7 en cuanto a la lectoescritura no se observan grandes mejorías (figuras 14 y 15).

Figura 14. GdO Cognoscitivo ISI

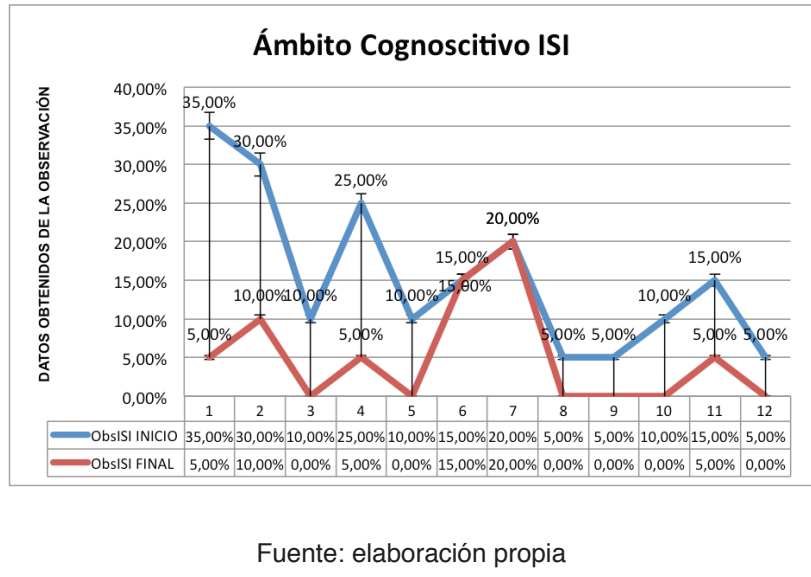

Figura 15. GdO Cognoscitivo ACL

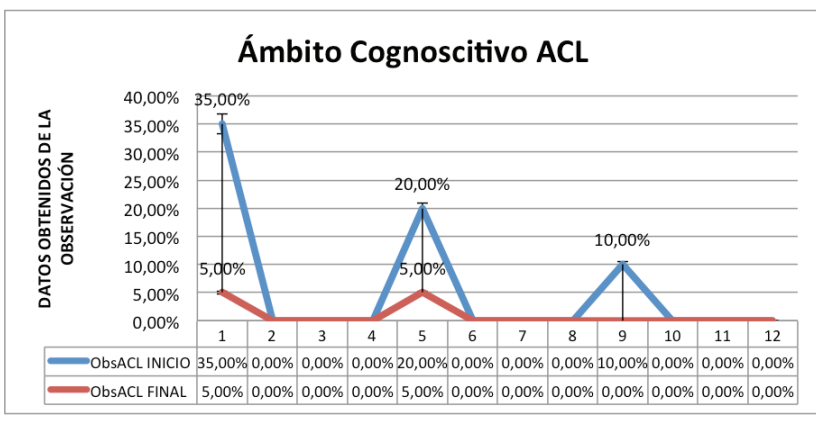

Fuente: elaboración propia 
En cuanto a los aspectos psicomotrices, los alumnos ven aumentadas significativamente sus capacidades gracias a los aspectos manuales de la realización de las dinámicas "El cine en tu cabeza", "Realización de videoarte personal" y el "Cortometraje grupal", en donde los discentes debían construir las escenografías y vestuarios, además del manejo de todos los equipos técnicos de un rodaje, como pueden ser los equipos de iluminación, sonido, producción y cámara (figuras 16 y 17). Se evidenció que dos alumnos de ACL poseían cierta dificultad a la hora de sostener con destreza los utensilios, a lo que se le intentó hacer ver su error para corregirlo. Pero el exceso de costumbre del alumno y la falta de tiempo necesario por parte de los docentes para una completa atención hizo imposible su mejoría.

Figura 16. GdO Psicomotor ACL

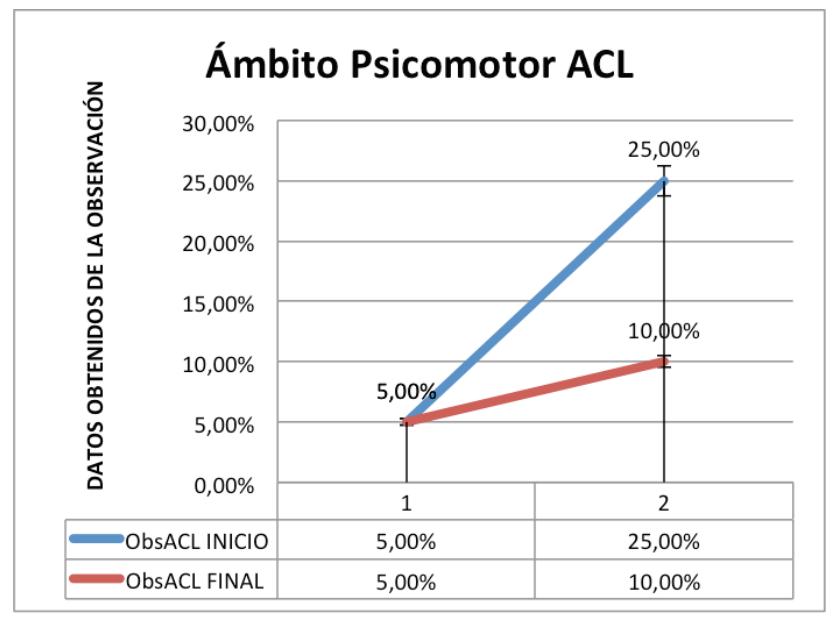

Fuente: elaboración propia

Figura 17. GdO Psicomotor ISI

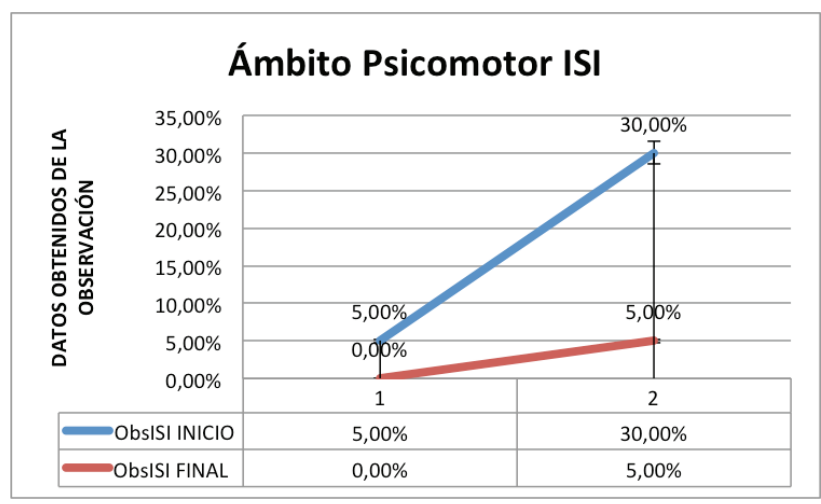

Fuente: elaboración propia
Con respecto al análisis de las mediciones psicosociales, se tiene que anotar que uno de los valores fundamentales del audiovisual es el trabajo en equipo, sin el cual sería imposible la realización de cualquier pieza compleja. Por eso se hizo especial hincapié en este sentido, sobre todo en el grupo ISI, donde se observó en un inicio a dos alumnos con muy baja capacidad de empatía y sentimiento de pertenencia, debido a una situación personal complicada. Durante las semanas siguientes se pudo ver que los alumnos poco a poco entraban en las dinámicas con mayor soltura y entendimiento con el resto de sus compañeros. Así se mostraron grandes mejorías en aspectos como la medición núm. 4, en donde las relaciones entre iguales dentro del grupo mejoraron $30 \%$. Al igual ocurrió con la motivación a la hora de realizar las actividades, donde en 25\% se vieron incrementados los estímulos hacia las dinámicas. Más dificultades se encontraron a la hora de mostrar los sentimientos, donde el nivel de mejoría fue más bajo, tan solo de $10 \%$. Al respecto de los estados de ánimo, las mejorías también fueron moderadas, siendo un reflejo común en discentes de estas edades.

En cuanto al grupo de ACL, se vio que sus aptitudes sociales de empatía también reflejaban una carencia importante, además de las referentes al trabajo en equipo, situación que se agravaba por la desmotivación que este tipo de alumnos suele sentir en ciertos momentos ante las carencias de estímulos. Gracias a las dinámicas pudieron ir entrando en los grupos, creando sus propias filias entre compañeros. Así queda reflejado en la medición núm. 9, donde la mejoría fue de $40 \%$ entre los alumnos, creando un buen ambiente en las dinámicas grupales. Situación importante de mejoría se vivió en cuanto a la expresión de los sentimientos (medición núm. 6), donde alumnos cuya expresividad emocional en un inicio fue muy baja consiguieron manifestar situaciones personales importantes en la dinámica de videoarte, expresando emociones abiertamente a todos sus compañeros. Además, esta situación ayudó a que los estados de ánimo cambiantes habituales entre discentes jóvenes (medición núm. 1) se vieran visiblemente mejorados, gracias a tener un mayor conocimiento de los compañeros y de sus sentimientos hacia situaciones comunes (figuras 18 y 19 ). 
Figura 18. GdO Psicosocial ISI

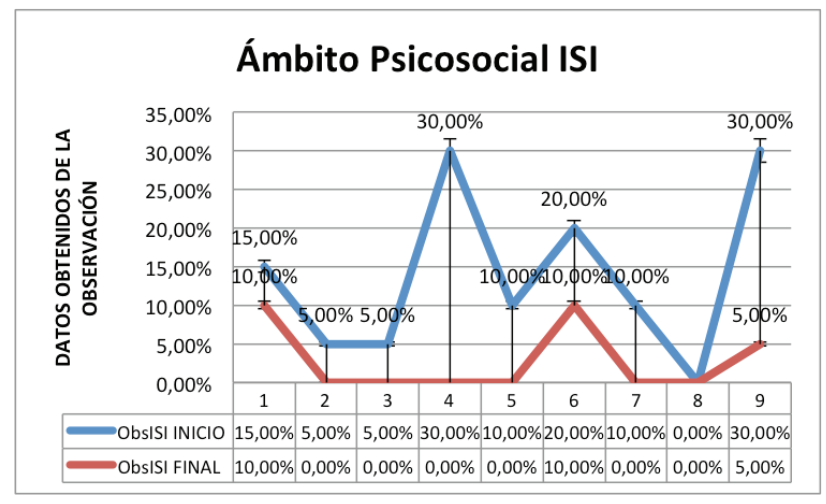

Fuente: elaboración propia

Figura 19. GdO Psicosocial ACL

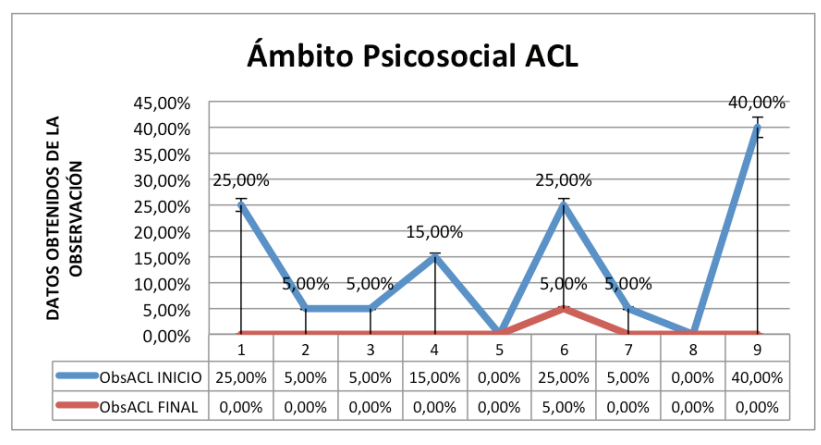

Fuente: elaboración propia

En el cuestionario final (CF), a los alumnos participantes de ISI y ACL el último mes del curso lectivo, se les preguntó si les sirvió como método de estudio en sus asignaturas el aprendizaje de la metodología G.A.C. y la respuesta fue mayoritariamente positiva, como se puede comprobar en la figura 20. Se anota que $25 \%$ de los alumnos no hicieron uso de la G.A.C. tras acabar el taller, justificando que les resultaba complicado dibujar, teniendo un alto sentimiento de frustración en este factor. Además, esos mismos alumnos que no hicieron uso de la metodología argumentaban una falta de motivación para esto, debido a la frustración artística.

Con el CF se quiso ver la respuesta de los alumnos a cuestiones planteadas en el $\mathrm{Cl}$ y observar si se producían cambios en su manera de entender las diferentes fases de análisis planteadas. Así, se comprobaron diferencias notables en cuanto a los métodos de trabajo, en donde $70 \%$ de los alumnos de ISI y $60 \%$ de los alumnos de ACL cambiaron de opinión al considerar más beneficiosos para ellos trabajar plasmando sus ideas propias y poder dirigir con tareas abiertas los trabajos a realizar. Además, los alumnos de ISI y ACL valoraron con $80 \%$ que se les daban mejor las tareas donde había que experimentar y manipular, cuando en el $\mathrm{Cl}$ marcaron otras opciones.

Figura 20. Uso de la G.A.C. por los alumnos participantes

\section{USO GAC AL CONCLUIR EL TALLER}

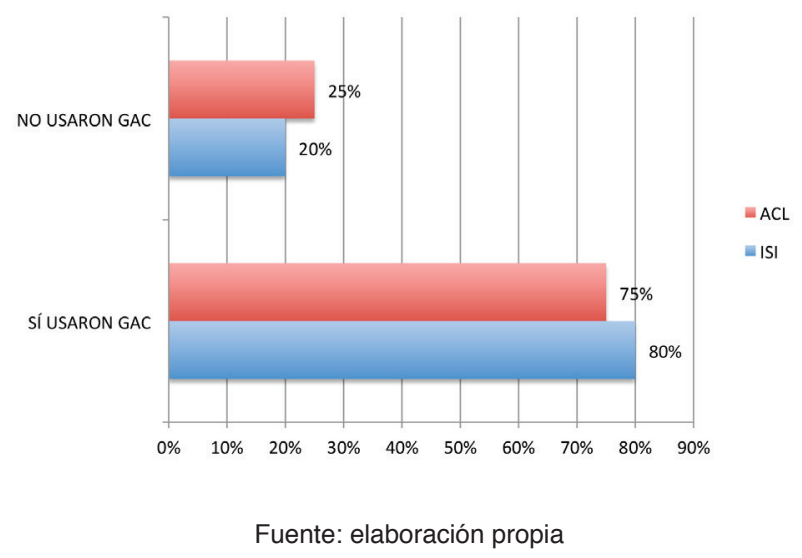

En cuanto a los métodos de estudio, los alumnos apoyaron mayoritariamente el uso de herramientas artísticas para sus estudios, complementando la lectura y la escritura, creyendo que sería beneficioso para una mejor comprensión de la asignatura.

Fue importante observar cómo discentes que -anteriormente habían marcado que nunca habían relacionado contenidos de otras asignaturas con la que estaban estudiando- habían comenzado a realizarlo consiguiendo una visión más global de los contenidos. El porcentaje de alumnos que así lo realizaron fue de $30 \%$ en el caso de ISI y $40 \%$ en el de ACL. Además, 90\% de alumnos tanto de ISI como de ACL contestaron que tras utilizar G.A.C. siguieron haciendo uso de los mapas mentales para el estudio de los temas de las asignaturas.

En relación con el sentimiento de pertenencia, afirmaron en los dos equipos de trabajo con 100\% que, tras la utilización de la metodología, se había creado un clima apropiado para el aprendizaje. Del mismo modo, aseguraron que se sentían orgullosos del grupo que se había formado. 


\section{CONCLUSIONES Y DISCUSIÓN}

La intervención de la metodología G.A.C. muestra una nueva herramienta para el profesorado, capaz de generar mayor atención y motivación al discente, entroncando directamente con las emociones, aportando un bagaje personal y emocional a los alumnos que disfrutarán unas clases donde saber explayarse, expandiendo sus conocimientos más allá de los reglados en los planes de estudio. El docente entiende el aula como un espacio escénico, donde poder narrar y disfrutar el arte de la interpretación, mostrando los conocimientos por medio de herramientas técnicas audiovisuales, plásticas o performativas y que lleven al alumno a través de las emociones del contenido educativo. Los resultados experimentales en la investigación cualitativa desarrollada muestran que los alumnos prefieren este tipo de métodos en comparación con el tradicional método de lección magistral propuesta por Brown y Atkins (1988).

Los alumnos han consolidado sus conocimientos en relación con las materias mostradas en las actividades G.A.C. realizadas. Como ya se ha marcado en la figura 16, son muchos los alumnos que han continuado usando G.A.C. tras finalizar su aprendizaje en el taller, y han mostrado gran satisfacción en su uso. La investigación continuará el próximo curso, analizando a los alumnos que ya han aprendido la metodología para intentar obtener datos referentes a su uso a largo plazo. Se intentará recabar información de las posibles mutaciones de la propia metodología G.A.C. por los propios alumnos -ya que esta metodología tiene un planteamiento vivo, el cual está abierto a cambios en cualquiera de sus ámbitos- y poder de esta manera crecer a modo de mapa conceptual con el tiempo.

Los datos cualitativos recogidos por parte de los alumnos han sido realmente satisfactorios. Se nombrará el caso del alumno ACL05 que, tras el aprendizaje metodológico G.A.C. y llegar a entender la técnica, lo llevó a la práctica en su propio ejercicio de videoarte, en donde desarrolló una síntesis gráfica formidable, con una analogía relacional de amor y muerte que todos los compañeros aplaudieron (figura 21).
Figura 21. Videoarte ACL05. Ejercicio grabado con Smartphone. Duración: 1 minuto

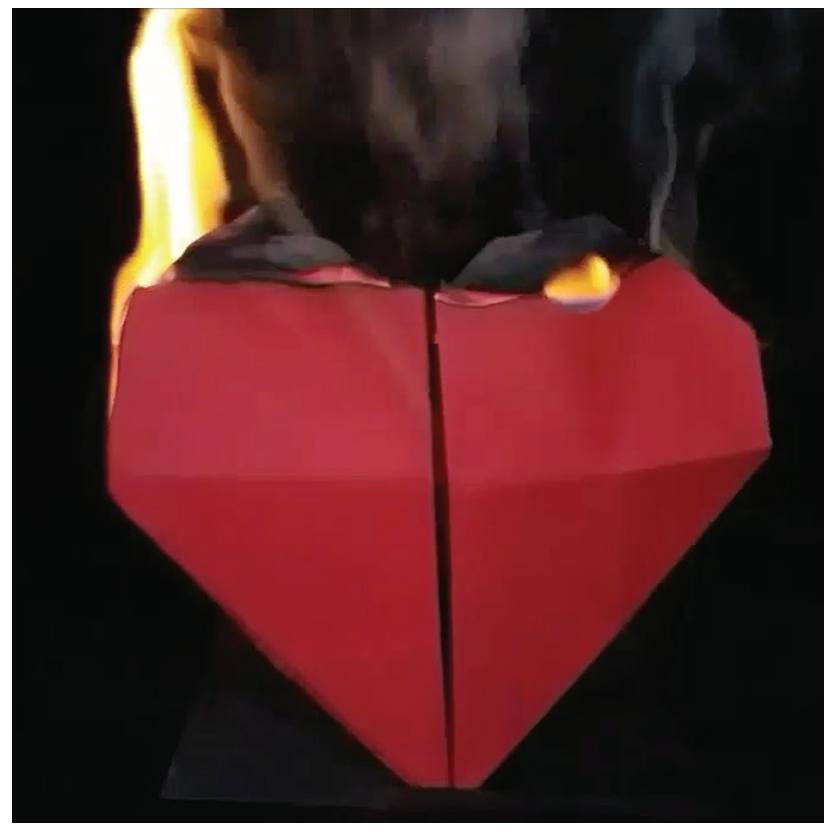

Desde el primer día de clase las emociones forman parte fundamental de todos los contenidos. Se intentan argumentar con historias narradas repletas de alegorías emocionales audiovisuales para introducir la alfabetización audiovisual. De esta manera, los alumnos tendrán vía libre para explicar sus sentimientos sin necesidad de hablar en primera persona, y mostrar estados psicológicos empáticos que ayuden al sentimiento de pertenencia por medio de sus compañeros. Este hecho fue patente en el CF a través de las mediciones CF24.1 y CF24.2, en donde alumnos como ISI02 reflejaron el sentimiento de pertenencia hacia sus compañeros y la satisfacción que ello le produjo (figura 22): 
Gráfica de Atención Completa (G.A.C.), una propuesta metodológica educativa mediante proyectos interdisciplinares para el aprendizaje y mejora de la capacidad de atención-concentración a través del audiovisual y el arte

Figura 22. Cuestionario alumno ISI02.

24.1

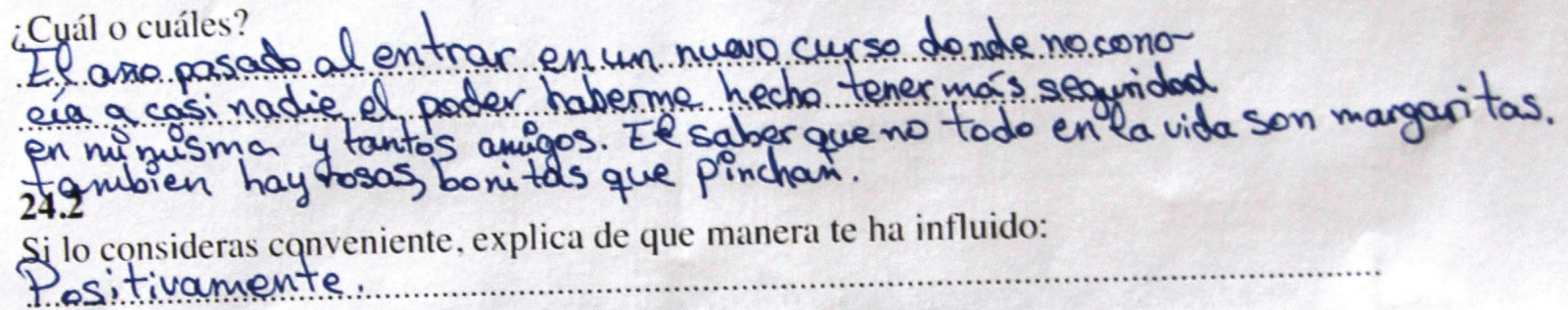

Por lo tanto, el sentimiento de pertenencia es casi tan importante como saber leer. Un alumno motivado siempre será un alumno aventajado en cuanto a esfuerzo, sabrá dosificar sus competencias y complementarse con el resto de sus compañeros, de modo que podrá desarrollar la habilidad de trabajar en equipo.

Cada alumno es único y sus motivaciones son distintas. El aprendizaje es múltiple y como tal, debe ofrecerse una visión múltiple de la educación para diseñar un nuevo modo de pensar en el discente. Así lo señalan en la entrada de su blog Arina Bokas y Rod Roca (Bokas, 2015), Cambiar el modo de pensar en Educación: cada alumno es único, publicada en The Huffington Post, sección de Educación. Las columnistas se basan en la investigación de Carol Dweck y hacen referencia a la teoría de las inteligencias múltiples de Howard Gardner para diseñar modos de pensar sobre el éxito en la educación, en un intento de conseguir una mayor potenciación de las habilidades de los estudiantes.

Esta metodología de trabajo, tanto para el profesor como para el alumno, requiere un esfuerzo ciertamente alto en sus primeras fases, en donde será necesario crear técnicas de creatividad. La metodología G.A.C. es una buena herramienta, capaz de aglutinar esa creatividad, conocimiento y diversión, y permitirá tanto al alumno como al profesor crear su propio discurso. La cultura debe circular en todos los sentidos, entretejiéndose a través de las asignaturas y desarrollar de esta forma lo que debería ser la base de toda educación escolar: la Interdisciplinariedad.
Por consiguiente, se sabe que para poder considerarla como una metodología global necesita tiempo, además de docentes que se atrevan a llevarla a cabo, apostando por los medios audiovisuales y sus posibilidades narrativas, permitiendo al alumno disfrutar de aulas dinámicas. Se entiende que las necesidades técnicas son en muchas ocasiones un obstáculo para muchos centros, pero con creatividad es posible suplir las técnicas, ya que las grabaciones hoy son más sencillas gracias a los teléfonos inteligentes. Para que G.A.C. funcione es importante que el docente adquiera esos conocimientos narrativos que se han expresado en la investigación y llegue a disfrutar la oratoria. Sin estos conceptos, será imposible conseguir que un alumno se emocione ante sus palabras.

Es importante anotar las carencias observadas de la metodología G.A.C., siendo conscientes de los pobres resultados en cuanto a lectoescritura, cuyo aspecto debe ser mejorado para los futuros cursos de puesta en práctica e investigación de la metodología. Son la escritura como la comprensión lectora dos puntos básicos para concebir buenos argumentarios y exposiciones de la materia a estudiar. Será interesante aunar fuerzas con otras metodologías cuyos resultados sean positivos en este ámbito y crear nuevas dinámicas que solucionen esta carencia.

Por otro lado, habrá que definir más dinámicas de trabajo individuales dentro del aula para poder abarcar el mayor número de asignaturas posibles. Es entendible que algunas asignaturas son más proclives al uso de ideogramas que otras y por eso, se debe preparar un mayor número de supuestos esce- 
narios a los que los discentes se puedan enfrentar en su etapa educativa.

Los datos de la investigación indican que la necesidad de alfabetización mediática es toda una realidad. Los alumnos piensan en imágenes, sueñan en imágenes y viven en imágenes. Han interiorizado todo el argumentario audiovisual dentro del devenir de sus acontecimientos diarios. Por lo tanto, la educación no puede vivir al margen. Se tiene que educar en y con el audiovisual.

Los alumnos se sienten cómodos dentro de contextos audiovisuales, saben expresarse y encontrar los argumentos necesarios para relacionarse con sus compañeros, así lo demuestran los datos de esta investigación. Son ellos los primeros en introducir nuevos conceptos audiovisuales a sus hábitos diarios. Los docentes deben ser parte de ellos.

Los profesores que están activos actualmente son los que han crecido con la televisión e Internet dentro de sus hogares. Pero también han conocido la etapa justamente anterior. En consecuencia, son los primeros en tener la necesidad de alfabetización, aprenderla y saber mostrarla.

Sin embargo, con la tan intrusiva LOMCE no se está dejando margen a los docentes para crear conocimientos en esta línea. Por lo tanto, se hace más necesario aún introducir la alfabetización mediática por otras vías dentro del sistema educativo y G.A.C. puede ser una herramienta adecuada a tal efecto.

Pero deberán ser los gobiernos en funciones los que realicen los cambios necesarios en sus Leyes de Educación, para que la alfabetización mediática sea un hecho. Hay que hacer ver a la sociedad que esta problemática puede convertirse en un asunto de gravedad, con la tan creciente manipulación mediática que se vive en los últimos años. Los medios de comunicación son conscientes de su poder y los poderes políticos no dudan en controlar aqueIlas vías de comunicación que permitan manipular a sus votantes. Es por eso que las personas deben estar preparadas ante toda la avalancha informativa que reciben, siendo además, las personas partícipes de ella, en cierta medida, gracias a plataformas como Twitter. La alfabetización mediática es una verdadera necesidad.

\section{REFERENCIAS}

Acaso, M. (2015). rEDUvolution. Hacer la revolución en la educación. Barcelona: Ediciones Paidós Ibérica.

Ainsworth, S. P., V. y Russel, T. (2011). Drawing to learn in science. Science. 333(6046), 10961097.

Álvarez, J. L. (2003). Cómo hacer investigación cualitativa, fundamentos y metodología. México D.F. : Editorial Paidós Mexicana S.A.

Andréu, J. G., A.; Pérez, A. M. (2007). Evolución de la teoría fundamentada como técnica de análisis cualitativo. Cuadernos Metodológicos $N^{\circ}$ 40.

Auchterlonie, T. (2014). El viaje del héroe: el argumento eterno [Gráfico]. Recuperado de http:// escrilia.com/el-viaje-del-heroe-el-argumentoeterno/.

Ausubel, D. (1963). The Psychology of Meaningful Verbal Learning. New York: Grune y Stratton.

Ausubel, D., Novak, D. y Hanesian, H. (1978). Educational Psychology: A Cognitive View. New York: Holt, Rinehart y Winston.

Bokas, A. (2015). Cambiar el modo de pensar de educación: cada alumno es único. Recuperado de http:/translate.google.com/translate?dep th $=1 \& \mathrm{hl}=$ es \&prev=search \&rurl=translate.google.es\&sl=en\&u=http://www.huffingtonpost. com/smart-parents/changing-the-mindset-ofe_b_7445856.html.

Brown, G. y. Atkins, M. (1988). Effective teaching in Higher Education. Londres: Ed. Routledge.

Campbell, J. (1949). The hero with a thousand faces. Nueva York: Bollingen Fundation Inc.

Campillo Ranea, J. E. (2010). La importancia de la educación emocional en las aulas. Recuperado de http://www.juntadeandalucia.es/educacion/ webportal/abaco-portlet/content/ab2f1 d46cd27-47f8-b849-e928a701df05. 
Gráfica de Atención Completa (G.A.C.), una propuesta metodológica educativa mediante proyectos interdisciplinares para el aprendizaje y mejora de la capacidad de atención-concentración a través del audiovisual y el arte

Flecha, R. y Puigvert, L. (2002). La comunidad de aprendizaje: una apuesta por la igualdad educativa. Rexe: Revista de Estudios y Experiencias en Educación, 1(1), 11-20.

Fortea, M. A. (2009). Metodologías didácticas para la enseñanza/aprendizaje de competencias.

García-Ruiz, R., Ramírez-García, A, RodríguezRosell, Ma. M. (2014). Educación en alfabetización mediática para una nueva ciudadanía prosumidora. Comunicar [en línea], XXI (juliodiciembre).

Gavara de Cara, J. C., Pérez Tornero, J. M. (2012). La alfabetización mediática y la Ley General de Comunicación Audiovisual en España (E. UOC Ed. 2012 ed.). Barcelona: UNESCO Institute for Inforation Technologies.

Goleman, D. (1996). Inteligencia Emocional. Madrid: Kairós.

González García, F. M. (1992). Los mapas conceptuales de J.D. Novak como instrumentos para la investigación en didáctica de las ciencias experimentales. Enseñanza de las Ciencias: Revista de Investigación y Experiencias Didácticas, 10 (2), 148-158.

Guillén, J. C. (2017). Neuroeducación en el aula, de la teoría a la práctica: Createspace Independent Publishing Platform.

Gutiérrez, A., Tyner, K. (2012). Educación para los medios, alfabetización mediática y competencia digital. Comunicar [en línea], XIX (s.f).

Marina, J. A. (2012). Neurociencia y Educación. Recuperado de http://www.joseantoniomarina. net/articulo/neurociencia-y-educacion/.

Mcluhan, M. (1972). La Galaxia Gutenberg: Génesis del "Homo Typographicus". Madrid: Aguilar S.A. de Ediciones.

Muñoz, E. (2010). Estructuración de los contenidos. pp. 25-34.

Pérez Tornero, J. M. (2008). Multi-screen society: a challenge for media literacy. [La sociedad multipantallas: retos para la alfabetización me- diática]. Comunicar, 31, 15-25. doi:https://doi. org/10.3916/c31-2008-01-002

Pública, C. S. d. E. (2010). Guía de observación para la detección de necesidades educativas especiales, con o sin discapacidad, en niños de educación básica. Recuperado de http://www. conafe.gob.mx/educacioncomunitaria/programainclusioneducativa/guia-educacion-basica. pdf.

Realinfluencers. (2017). 8 metodologías que todo profesor del siglo XXI debería conocer. Recuperado de http://www.realinfluencers. es/2017/03/02/8-metodologias-profesor-sigloxxi-deberia-conocer

Revista Educación 3.0. (2016). Método alternativo para la enseñanza de las matemáticas. Recuperado de http://www.educaciontrespuntocero. com/recursos/metodos-alternativos-para-la-ensenanza-de-las-matematicas/32992.html/

Robinson, K. (2010). La revolución del aprendizaje [ponencia presentada en la Conferencia Oficial de TED. Longbeach, California.

Sánchez-Escalonilla, A. (2009). Fantasía de aventuras. Claves creativas en novela y cine. Barcelona: Ariel.

Sandoval, Y. y Aguaded, J. I. (2012). Nuevas audiencias, nuevas responsabilidades. La competencia mediática en la era de la convergencia digital. Icono 14, 10 (3), 8-22. doi:10.7195/ri14.v10i3.197

Sousa, D. A. (2014). Neurociencia educativa: Mente, cerebro y educación. Madrid: Narcea Ediciones S.A.

Stewart, J., Van Kirk, J. y Rowell, R. (1979). Concept Maps: a tool for use in biology teaching. The American Biology Teacher, 41 (3), 171-175.

Strauss, A. L. y. Corbin, J. (1990). Basics of qualitative research: grounded theory, procedures and techniques. Newbury Park, CA.: Sage publications. 
Thompson, K. (1999). Storytelling in the New HoIlywood. Understanding Classical Narrative Technique. Cambridge: Harvard University Press.

Tokuhama-Espinosa, T. (2011). Mind, Brain, and Education Science: A Comprehensive Guide to the new brain-based teaching. United States Of America: W. W. Norton \& Company.

Tokuhama-Espinosa, T. (2017). El cerebro y el aprendizaje - Formación docente en el siglo XXI. Recuperado de: http://traceytokuhama.com/index.php?option=com_tz_ portfolio\&view $=$ article\&id $=437$ :el-cerebro-yel-aprendizaje-formacio-n-docente-en-el-sigloxxi\&catid=23\&ltemid=335.

Vizcaíno, P. (2016). Del storytelling al storytelling publicitario: el papel de las marcas como contadoras de historias. Universidad Carlos III de Madrid.

Vogler, C. (2002). El viaje del escritor. Barcelona, España: RobinBook, S.L. 